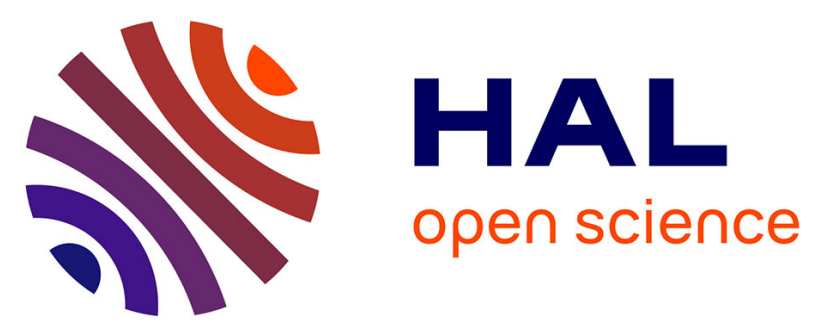

\title{
Relative Sea-Level Changes Over the Past Centuries in the Central Ryukyu Arc Inferred From Coral Microatolls
}

J. Weil-accardo, N. Feuillet, K. Satake, T. Goto, K. Goto, T. Harada, H. Kayanne, M. Nakamura, N. Ramos, J.-m. Saurel, et al.

\section{To cite this version:}

J. Weil-accardo, N. Feuillet, K. Satake, T. Goto, K. Goto, et al.. Relative Sea-Level Changes Over the Past Centuries in the Central Ryukyu Arc Inferred From Coral Microatolls. Journal of Geophysical Research : Solid Earth, 2020, 125 (2), 10.1029/2019JB018466 . insu-03164037

\section{HAL Id: insu-03164037 https://hal-insu.archives-ouvertes.fr/insu-03164037}

Submitted on 12 Mar 2021

HAL is a multi-disciplinary open access archive for the deposit and dissemination of scientific research documents, whether they are published or not. The documents may come from teaching and research institutions in France or abroad, or from public or private research centers.
L'archive ouverte pluridisciplinaire HAL, est destinée au dépôt et à la diffusion de documents scientifiques de niveau recherche, publiés ou non, émanant des établissements d'enseignement et de recherche français ou étrangers, des laboratoires publics ou privés. 


\section{JGR Solid Earth}

\author{
RESEARCH ARTICLE \\ 10.1029/2019JB018466 \\ Key Points: \\ - Relative sea-level changes due to \\ climate and tectonics recorded by \\ coral microatolls \\ - Record of vertical deformations \\ related to the seismic cycle of the \\ Ryukyu subduction zone \\ - Coupling variability of the Ryukyu \\ subduction zone
}

Supporting Information:

- Supporting Information S1

Correspondence to:

J. Weil-Accardo,

weil@cerege.fr

Citation:

Weil-Accardo, J., Feuillet, N., Satake, K., Goto, T., Goto, K. Harada, T., et al. (2020). Relative sea-level changes over the past centuries in the central Ryukyu Arc inferred from coral microatolls. Journal of Geophysical Research: Solid Earth, 125, e2019JB018466. https:// doi.org/10.1029/2019JB018466

Received 29 JUL 2019

Accepted 5 DEC 2019

Accepted article online 7 DEC 2019

(C)2019. American Geophysical Union. All Rights Reserved.

\section{Relative Sea-Level Changes Over the Past Centuries in the Central Ryukyu Arc Inferred From Coral Microatolls}

\author{
J. Weil-Accardo ${ }^{1,2}$, N. Feuillet ${ }^{3}$, K. Satake ${ }^{2}$, T. Goto ${ }^{2}$, K. Goto ${ }^{4}$, T. Harada ${ }^{2}$, H. Kayanne ${ }^{5}$, M. \\ Nakamura $^{6}$, N. Ramos ${ }^{7}$, J.-M. Saurel ${ }^{3}$, K. Sowa ${ }^{8}$, S.-C. Liu' ${ }^{9}$, T.-L. Yu ${ }^{1,9,10}$, and C.-C. Shen ${ }^{1,9,10}$ \\ ${ }^{1}$ Now at CEREGE, Aix-Marseille University, Aix-en Provence, France, ${ }^{2}$ Earthquake Research Institute, University \\ of Tokyo, Tokyo, Japan, ${ }^{3}$ Institut de Physique du Globe de Paris, Sorbonne Paris University, Paris-Diderot University, \\ UMR 7154, Paris, France, ${ }^{4}$ International Research Institute of Disaster Science, Tohoku University, Sendai, Japan, \\ ${ }^{5}$ Department of Earth and Planetary Science, University of Tokyo, Tokyo, Japan, ${ }^{6}$ Faculty of Science, University \\ of the Ryukyus, Okinawa, Japan, ${ }^{7}$ National Institute of Geological Sciences, University of the Philippines-Diliman, \\ Quezon City, Philippines, ${ }^{8} \mathrm{Japan}$ Agency for Marine-Earth Science and Technology, Kanagawa, Japan, ${ }^{9}$ Department \\ of Geosciences, National Taiwan University, Taipei, Taiwan, ROC, ${ }^{10}$ Research Center for Future Earth, National Taiwan \\ University, Taipei, Taiwan, ROC
}

Abstract This study focuses on Okinawa and Yoron islands, in order to better understand tectonics in the Ryukyu Arc related to the subduction zone. We used coral microatolls-known for their centimetric accuracy in the record of relative sea-level (RSL) changes— to reconstruct RSL changes over the last century from living microatolls. A fossil microatoll in Yoron was used to discuss possible RSL changes beyond the last century. The signal consists of emergence whose rate varies through time, interrupted by decadal to multidecadal periods of sudden and/or gradual submergence and by interannual sea-level falls. Comparison with other existing RSL records in the arc highlights RSL variability along the arc. This pattern contrasts with the homogeneous and linear absolute regional sea-level rise, implying that this latter signal cannot fully explain our observations and that an additional process is required. We suggest the subduction zone as a possible source for generating centimetric scale RSL changes observed in coral microatolls. We tested how the Ryukyu megathrust could explain our observations with elastic dislocation modeling. The emergence trend could be explained by interseismic loading on the plate interface with a minimum coupling rate of $25 \%$, which is higher than previous estimates based on short instrumental records. As for the submergence events that occurred regularly in the coral record, we show that they could be explained by slow slip events on the shallower part of the megathrust or in the transition zone. Such process could accommodate a significant part of the total convergence.

\section{Introduction}

Since the occurrence of three megathrust earthquakes having triggered devastating tsunamis in 2004 in Sumatra, 2010 in Chile, and 2011 in Japan, we cannot exclude the possibility that any subduction zone may produce megathrust earthquakes. It is thus essential to better constrain the seismic potential of poorly known subduction zones, where the historical record of large earthquakes is short and where the recurrence interval of large earthquakes is long.

The Ryukyu subduction zone, along which the Philippine Sea Plate subducts beneath the Eurasian Plate at a rate of $8 \mathrm{~cm} /$ year, presents an active back-arc spreading in the Okinawa trough. This characterizes an extensional regime usually associated with a weak interplate coupling (Scholz \& Campos, 1995). Based on the seismic moment released over the last century, the seismic coupling of the Ryukyu subduction was estimated to be lower than 5\% (Peterson \& Seno, 1984). The modeling of GPS data scattered on all islands of the arc also indicates a low coupling rate varying between 5\% in the central Ryukyu Arc and 35\% in the southern Ruykyu Arc (Yaeyama islands and Miyako island, Watanabe \& Tabei, 2004). Overall, all the existing data concur to conclude that the Ryukyu subduction zone might be unable to generate large thrust earthquakes. The recent discovery of slow slip event (SSE) of different natures all along the plate boundary at depth ranging between 0 and 60 km (Heki \& Kataoka, 2008; Nishimura, 2014; Nakamura \& Sunagawa, 

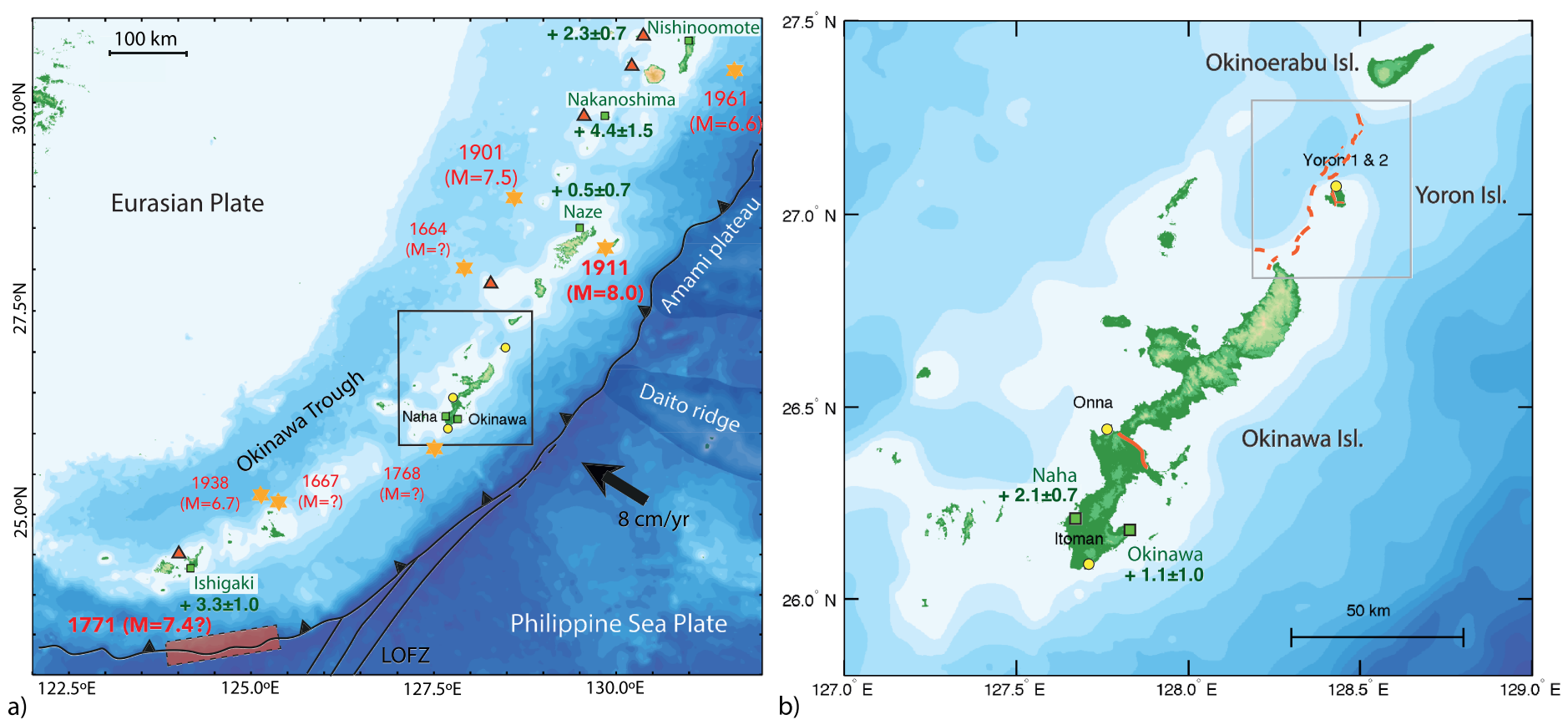

Figure 1. Geodynamic setting of the Ryukyu Arc. (a) Bathymetry and topography: ASTER data. Black rectangle (panel b): investigated area in 2016 (south Okinawa to north of Okinoerabu) with the three samples sites of Itoman, Onna, and Yoron (yellow dots). Orange stars: location, ages, and magnitudes of historical EQ based on Nakata and Kawana (1995). Red rectangle: rupture source of the 1771 Yaeyama earthquake (Nakamura, 2009b). Red triangles: active volcanoes. Green squares: Tide gauges (PSMSL data) with rate in millimeter per year (linear regression on annual data, Figure 10). LOFZ: Luzon-Okinawa Fracture Zone. (b) Location of the investigated sites and active faults (red lines and dashed lines). Bathymetry and topography: ASTER data. Yellow dots: studied sites. Green squares: Naha and Okinawa tide gauges. Major submarine faults (dashed red lines) between Yoron and north of Okinawa, and onshore faults (red lines) in Yoron from Goto et al. (2018). Gray rectangle: limit of the study of Goto et al. (2018). Major onshore fault in Okinawa from IAIST (2016).

2015) may indicate that the megathrust could use a discrete mechanism to release most of the accumulated strains instead of rupturing during large earthquakes.

On the basis of simple elastic models, however, Ando et al. (2009) highlighted the fact that the onland GPS stations are probably too far away to determine the coupling rate of the interface near the trench if the coupled area is less than 50-km wide. They further highly recommended acquiring offshore monitoring of crustal deformation. This was done a few years later in the central Ryukyu Arc, off the Okinawa main island (Nakamura, 2011; Tadokoro et al., 2018). In this region, data from GPS/acoustic instruments revealed the existence of a strongly coupled 20- to $30-\mathrm{km}$ wide patch located southeast of Okinawa, with lateral extent that still remains to be accurately constrained (Tadokoro et al., 2018). Those results show that at least some portions of the plate interface, close to the trench, may be coupled. Recently, Lin et al. (2014) showed that several geological and geophysical similarities exist between the Sumatra and the Ryukyu subduction zones (the stress regime, the presence of subducting reliefs and high gravity anomalies, and the distribution of the seismicity) and concluded that a megathrust event is highly likely, particularly in the central Ryukyu Arc. Moreover, based on a new lithospheric density model, Doo et al. (2018) inferred a strong plate coupling in southern Ryukyu.

All these studies highlight the fact that the seismic coupling of the plate interface of the Ryukyu subduction zone and thus its capability to generate large earthquake is still very controversial. This is mainly because we are missing a long record of earthquakes in this area. Only few M8+ earthquakes or tsunamis were reported over the last 350 years (Watanabe, 1985), the source of which is still highly debated, and the historical record is too short to estimate their recurrence time.

With run-up of waves up to 30-m high, and more than 17,000 casualties, the 1,771 Meiwa tsunami was the deadliest event reported along the Ryukyu Arc (Nakata \& Kawana, 1995). It occurred in the southern Ryukyu (Figure 1a), and several sources are proposed for this event, among them are reverse faulting coupled with landslides, an arc-perpendicular normal fault located to the east of Ishigaki island (Nakamura, 2006, and 
references therein), a thrust earthquake at the plate interface at shallow depth (Nakamura, 2009b), and a massive collapse of the accretionary wedge prism close to the trench (Okamura et al., 2018).

The strongest M8+ earthquake reported in the Ryukyu area occurred on 15 June 1911 in the area of Kikai or Amami islands (Figure 1a) and killed 12 people. The epicenter of this event is not well constrained and estimates vary by up to $200 \mathrm{~km}$. This earthquake was large enough to produce a tsunami of $5 \mathrm{~m}$ in Kikai. Two main sources were proposed for this event: an intermediate intraslab earthquake beneath Amami and a shallow interplate earthquake in front of Kikai, the second hypothesis being more compatible with the occurrence of a tsunami (references therein Goto, 2013).

The reexamination of historical records highlighted two additional historical tsunamis that occurred in 1768 and 1791 in Okinawa Island and that could have been induced by interplate M-class 8 earthquakes on the coupled patch revealed by the offshore GPS measurements (Nakamura, 2011; Tadokoro et al., 2018).

The 1771 Meiwa tsunami dislodged and displaced huge coral boulders and sediments far from the coast (Ando et al., 2018; Goto, Miyagi, et al., 2010). A systematic mapping and dating of numerous boulders transported along the coast of several islands of the arc allowed the identification of other older tsunamis of different magnitude and with estimated recurrence intervals of 140-400 years over the last 2,400 years (Araoka et al., 2013; Goto, Shinozaki, et al., 2010; Goto, Miyagi, et al., 2010; Goto, Kawana, et al., 2010). Based on the analysis of the sediment stratigraphy along the coast of Ishigaki in southern Ryukyu, Ando et al. (2018) identified four tsunami deposits, probably triggered by ruptures of the plate interface, that occurred in the area over the last 2,500 years with a recurrence time of about 600 years.

Those results are in contrast with the inferences based on short-term records such as GPS and seismological data. This illustrates that existing models fail to predict earthquake recurrence over the long term. For the Ryukyu subduction zone, difficulty in using the GPS to constrain the coupling rate may also arise because rigid block motions along many tectonic structures in the area are superimposed on the strain accumulation signal (Nakamura, 2004). This problem could be avoided by using the vertical motion of the GPS (Aoki \& Scholz, 2003), but it is often noisy and rarely used, particularly when the record is short. We also know that the interseismic strain rate may vary through time during one seismic cycle and between seismic cycles (e.g., Meltzner et al., 2015). We thus really need to enlarge the rather short time window provided by instrumental records and to gather longer records to establish long time-series.

Toward this goal, by taking advantage of the ubiquitous corals in subtropical areas in southwest Japan, we started to study the coral microatolls along the Ryukyu Arc in order to provide several decades to several centuries-long measurements of the vertical deformation due to the seismic cycle at the plate interface.

Coral microatolls are massive coral colonies that live on shallow reef flats, and act as natural tide gauges by recording relative sea-level (RSL) changes with a precision of a few centimeters over several centuries or millennia (e.g., Meltzner \& Woodroffe, 2015). We use the coral microatoll record to retrieve the history of strain accumulation and release along the megathrust interface over the whole seismic cycle.

Coral microatolls are one of the valuable geological markers filling the gap between short-term deformation measured by instrumental geodesy and longer-term deformation recorded by older geological markers such as marine terraces. In addition to its tectonic significance, the coral microatolls record a significant climatic component (any changes of the absolute sea level) that we also need to characterize and which is of prime importance for islands that are especially vulnerable to the global climate change through induced regional sea-level changes.

We present here the first study using the annual record preserved in coral microatolls in Japan to accurately reconstruct RSL changes related to tectonic processes at subduction zones and to the climate. Previous works were dedicated to the survey and the ${ }^{14} \mathrm{C}$ dating of the edges of mid- to late-Holocene fossil microatolls in south Ryukyus (Ota et al., 1985) and on the east of Okinawa (Fujita et al., 2015).

We focused our first investigation in the central Ryukyu Islands where we observed microatolls on all islands we visited. We collected five samples in Okinawa main island and in Yoron Island. We first briefly review the methodology and present the main results including the detailed mapping of all the sites we investigated, the x-ray of the corals we sampled, and the RSL reconstructions. Then, by using the regional tide-gauges and satellite altimetry, we discuss the signal recorded by our microatolls and estimate the climatic component. 
Finally, by using simple elastic dislocation forward modeling, we discuss the origin of the coral signal to get information on the coupling rate and past tectonic events in the central Ryukyu Arc.

\section{Methodology}

\subsection{The Use of Microatolls as Paleogeodetic Tool}

The term "microatoll" is used to describe the specific morphology of massive coral colonies living in the intertidal zone and whose upper growth is limited by the RSL changes. The coral begins to grow radially with a ball-shape without constraining its upward growth by low tides or effect of exposure (hereafter named "unconstrained" upward growth or environment). Once the coral reaches its highest level of survival (HLS), which is the theoretical surface beyond which the coral cannot survive due to subaerial exposure (Meltzner et al., 2010), its upward growth is limited by the fluctuation of its HLS, and it mainly grows outward. The coral thus adapts its upward growth following the changes of this level and develop a microatoll morphology. The HLS is typically related to the lowest tide of the year (Meltzner et al., 2010), even though the accurate relationship between the HLS and the tidal range varies between species (Briggs et al., 2006; Meltzner et al., 2006; Natawidjaja et al., 2006) and among corals depending on the coral's environment (e.g., Smithers \& Woodroffe, 2000; Weil-Accardo, Feuillet, Jacques, Deschamps, Saurel, et al., 2016). Since RSL changes generate concomitant HLS fluctuations (Zachariasen et al., 1999, 2000), the coral adapts its growth in response to RSL changes. In this way, a coral evolving in a stable sea level will mainly grow outward and develop a flat shape. In a submergent environment, the upward growth is promoted, generating a cup morphology with a higher external rim surrounding an older central part. Corals that are growing in an emergent setting will tend to display a hat morphology with a higher central part surrounded by a lower external living rim (e.g., Hopley, 2011; Stoddart \& Scoffin, 1979; Scoffin et al., 1978; Taylor et al., 1987). Corals record seasonal changes in aragonite density in their skeleton, which leads to an alternation of dark and light bands that corresponds to the annual banding, similar to tree rings. By observing the coral's internal chronology, we can accurately date the RSL changes recorded by the coral.

We use coral microatolls to document vertical deformation due to megathrust seismic cycle. Indeed, for simple models of the seismic cycle, for which the crust behaves elastically over one or few seismic cycles, the overriding plate subsides slowly above the locked (coupled) zone and uplifts beyond when the stress accumulates during the interseismic period. The vertical deformation of the upper plate is strictly of the opposite sign (uplift above the ruptured zone and subsidence beyond) during the earthquake when the stress is suddenly released.

Microatolls have been used elsewhere and have provided important results that allowed to improve our knowledge of the seismic cycle at tropical subduction zones in Indonesia (e.g., Meltzner et al., 2015, 2010, 2012, 2006; Natawidjaja et al., 2006; Philibosian et al., 2012; Sieh et al., 2008; Zachariasen et al., 1999), in Vanuatu (Taylor et al., 1980, 1982), in the Lesser Antilles (Weil-Accardo, Feuillet, Jacques, Deschamps, Beauducel, et al., 2016), in Bangladesh (Mondal et al., 2018), and in Myanmar (Shyu et al., 2018).

\subsection{Survey and Sampling}

Fieldwork was conducted in March 2016 to search for coral microatolls in the central part of the arc between north of Okinoerabu and south of Okinawa (Figure 1a). With the good resolution of satellite images and submarine pictures available on Google Earth over the investigated area, we were able to identify several promising sites, and we did not perform additional flight surveys during the fieldwork.

The Ryukyu Arc is characterized by a large tidal range of $2 \mathrm{~m}$ on average. We took care to avoid microatolls that were localized in moated pools that are not freely connected to open ocean, as this moating effect usually prevails in areas affected by a large tidal range (Hopley, 1982). In ponds, the lower part of the tidal cycle is often truncated implying a lowest sea level in the pond higher than in the open ocean (Smithers, 2011). In consequence, moated microatolls will record sea-level changes of the pool rather than true RSL changes. Without additional historical information and measurements to reconstruct the history of a moated microatoll, we cannot not use them to reconstruct the RSL variations.

We selected four sites (GPS locations in Table 1), two in the main Okinawa island and two in Yoron island (see detailed information in the following). We performed a detailed survey of all the sites with a total station to measure accurately the modern HLS recorded by each coral. We thus verify that all contemporary microatolls of the site are recording the HLS at the same elevation. This control is of prime importance in choosing the best corals that will give us a relevant record of RSL in the site and avoid the odd coral out 
Table 1

GPS Location of the Investigated Sites

\begin{tabular}{lll}
\hline Site name & Latitude & Longitude \\
\hline Itoman & $26^{\circ} 05^{\prime} 20.06 ” \mathrm{~N}$ & $127^{\circ} 42^{\prime} 29.27^{\prime \prime} \mathrm{E}$ \\
Onna & $26^{\circ} 26^{\prime} 30.64 ” \mathrm{~N}$ & $127^{\circ} 46^{\prime} 02.32^{\prime \prime} \mathrm{E}$ \\
Yoron site 1 (living microatolls) & $27^{\circ} 04^{\prime} 13.49^{\prime \prime} \mathrm{N}$ & $128^{\circ} 25^{\prime} 49.13^{\prime \prime} \mathrm{E}$ \\
Yoron site 2 (fossil microatolls) & $27^{\circ} 04^{\prime} 05.43 ” \mathrm{~N}$ & $128^{\circ} 25^{\prime} 31.17^{\prime \prime} \mathrm{E}$ \\
\hline
\end{tabular}

Note. Location on maps in Figure 1. (overturned or tilted corals, corals affected by substrate changes or any very local changes not representative of the RSL changes of the whole site).

After the topographic surveys, we sampled five 10-cm-thick coral slabs with a hydraulic chain saw in June and July 2016. Thin cutting of the coral slabs was further performed at the Ogyu Manufacturing Inc., also known in Japan as Milano Seisakusho Co. Ltd (equipped with stable diamond wire), where we obtained slices of about 1 to $2 \mathrm{~cm}$ of thickness. The thin slices were then x-rayed at the Veterinary Medical Center of the University of Tokyo. Details about the methodology, total station measurements, sampling, thin cutting at the marble mason, and coral x-rays were given in several previous publications (e.g., Weil-Accardo, Feuillet, Jacques, Deschamps, Beauducel, et al., 2016).

U-Th dating was needed to constrain the RSL history recorded by one fossil coral sampled in Yoron. Ages are presented in Table 2 (see details of metholology in Table 2 caption and overall descriptions of the methodology in previous papers, e.g., Cheng et al., 2000; Jaffey et al., 1971).

\subsection{Coral Stratigraphy and Reconstruction of RSL Changes}

The coral morphology (flat, cup, or hat shape) may give us an indication about the past RSL changes, but this is not always sufficient since regrowth colonies may cover the surface of the main colony and thus mask the RSL fluctuations. A subtle stratigraphic analysis of the large cross-sectional slabs collected from microatolls is needed to provide evidence of the changes that have affected the coral during its growth (period of promoted upward growth, period with frequent HLS impingements, changes in basal topography of the coral, etc.).

The x-ray image reveals the annual density bands of the coral and multiple old HLS surfaces. We measured the changes in elevation of each HLS surface and established their chronology by counting the annual growth bands. From this stratigraphy and by plotting the maximum elevation of each growth band versus time, we obtain the graph of HLS elevation through time (with 0 as the reference elevation corresponding to the highest elevation of the youngest external growth band).

We have distinguished the "HLS year" when coral upward growth is limited by its HLS and the "highest level of growth (HLG) year," when the coral did not reach its theoretical HLS (e.g., Zachariasen et al., 1999, 2000). During HLG years, the coral upward growth is only limited by its natural growth rate, and the distance to its theoretical HLS is unknown (Meltzner et al., 2010). In the coral stratigraphy, a HLS year corresponds to a truncated growth band, while the growth band is complete during a HLG year (Zachariasen et al., 2000).

The coral upward growth is often disrupted by temporary centimetric sea-level drops, commonly named "die downs" (Taylor et al., 1987; Zachariasen et al., 1999). We use the term HLS for years that follow a die down while the term HLG is used for years not immediately following a die down (Meltzner et al., 2010).

To calculate the submergence and emergence rate for each coral, we use the different calculation methods of Zachariasen (1998), Zachariasen et al. (2000), and Meltzner et al. (2010) that give similar results and

Table 2

Uranium and Thorium Isotopic Compositions and 230th ages of Yoron Fossil Microatoll by MC-ICPMS, Thermo Electron Neptune, at NTU

\begin{tabular}{|c|c|c|c|c|c|c|c|c|}
\hline \multirow{2}{*}{$\begin{array}{l}\text { Sample } \\
\text { ID }\end{array}$} & \multirow{2}{*}{$\begin{array}{l}{ }^{238} \mathrm{U} \\
10^{-9} \mathrm{~g} / \mathrm{g}^{\mathrm{a}}\end{array}$} & \multirow{2}{*}{$\begin{array}{l}{ }^{232} \mathrm{Th} \\
10^{-12} \mathrm{~g} / \mathrm{g}\end{array}$} & \multirow{2}{*}{$\begin{array}{l}\delta^{234} \mathrm{U} \\
\text { measured }^{\mathrm{b}}\end{array}$} & \multirow{2}{*}{$\begin{array}{l}{\left[{ }^{230} \mathrm{Th} /{ }^{238} \mathrm{U}\right]} \\
\text { activity }^{\mathrm{c}}\end{array}$} & \multirow{2}{*}{$\begin{array}{l}{\left[{ }^{230} \mathrm{Th} /{ }^{232} \mathrm{Th}\right]} \\
\text { atomic }\left({ }^{*} 10^{-6}\right)\end{array}$} & \multicolumn{2}{|c|}{ Age (yr ago) } & \multirow{2}{*}{$\begin{array}{l}\delta^{234} U_{\text {initial }} \\
\text { corrected }^{\mathrm{b}}\end{array}$} \\
\hline & & & & & & uncorrected & corrected $^{\mathrm{c}, \mathrm{d}}$ & \\
\hline YOR-F1-1 & $2856.0( \pm 3.5)$ & $199.6( \pm 5.2)$ & $143.0( \pm 2.0)$ & $0.001166( \pm 0.000023)$ & $275.2( \pm 8.9)$ & $111.3( \pm 2.2)$ & $109.7( \pm 2.3)$ & $143.1( \pm 2.0)$ \\
\hline YOR-F1-2 & $2633.2( \pm 3.6)$ & $116.0( \pm 4.7)$ & $146.0( \pm 1.9)$ & $0.001631( \pm 0.000028)$ & $610( \pm 27)$ & $155.3( \pm 2.7)$ & $154.3( \pm 2.7)$ & $146.1( \pm 1.9)$ \\
\hline YOR-F1-4 & $2579.1( \pm 3.7)$ & $105.6( \pm 4.6)$ & $144.4( \pm 2.3)$ & $0.002473( \pm 0.000024)$ & $996( \pm 44)$ & $235.8( \pm 2.3)$ & $234.9( \pm 2.4)$ & $144.5( \pm 2.3)$ \\
\hline YOR-F1-6 & $3114.0( \pm 3.0)$ & $339.0( \pm 4.5)$ & $146.7( \pm 1.7)$ & $0.003415( \pm 0.000032)$ & $517.2( \pm 8.4)$ & $325.3( \pm 3.1)$ & $322.7( \pm 3.4)$ & $146.8( \pm 1.8)$ \\
\hline
\end{tabular}

Note. Analytical errors are $2 \sigma$ of the mean.

${ }^{\mathrm{a}}\left[{ }^{238} \mathrm{U}\right]=\left[{ }^{235} \mathrm{U}\right] \times 137.77\left( \pm 0.11 \%\right.$ ) $\left(\right.$ Hiess et al., 2012); $\delta^{234} \mathrm{U}=\left(\left[{ }^{234} \mathrm{U} /{ }^{238} \mathrm{U}\right]_{\text {activity }}-1\right) \times 1000 .{ }^{\mathrm{b}} \delta^{234} \mathrm{U}_{\text {initial }}$ corrected was calculated based on ${ }^{230} \mathrm{Th}$ age $(\mathrm{T})$, e.g., $\delta^{234} \mathrm{U}_{\text {initial }}=\delta^{234} \mathrm{U}_{\text {measured }} * \mathrm{e}^{\lambda_{234} * T}$, and $\mathrm{T}$ is corrected age. ${ }^{c}\left[{ }^{230} \mathrm{Th} /{ }^{238} \mathrm{U}\right]_{\text {activity }}=1-\mathrm{e}^{-\lambda_{230} * T}+\left(\delta^{234} \mathrm{U}_{\text {measured }} / 1000\right)\left[\lambda_{230} /\left(\lambda_{230}-\lambda_{234}\right)\right]\left(1-\mathrm{e}^{-\left(\lambda_{230}-\lambda_{234}\right) * T}\right)$, where $\mathrm{T}$ is the age. Decay constants are $9.1705 \times 10^{-6} \mathrm{yr}^{-1}$ for ${ }^{230} \mathrm{Th}, 2.8221 \times 10^{-6} \mathrm{yr}^{-1}$ for ${ }^{234} \mathrm{U}$ (Cheng et al., 2013), and $1.55125 \times 10^{-10} \mathrm{yr}^{-1}$ for ${ }^{238} \mathrm{U}$ (Jaffey et al., 1971). ${ }^{\mathrm{d}} \mathrm{Age}$ corrections, relative to chemistry date on January $13 \mathrm{th}, 2017$, were calculated using an estimated atomic ${ }^{230} \mathrm{Th} /{ }^{232} \mathrm{Th}$ ratio of $4( \pm 2) \times 10^{-6}$ (Shen et al., 2008) 
allow us to test the robustness of the coral signal. These methods are all based on linear regression, and the difference lies in the number and type of data taken into account in the calculation: all HLG and HLS data starting from the first HLS (Zachariasen, 1998; Zachariasen et al., 2000), only HLS data (Zachariasen, 1998; Zachariasen et al., 2000), only noneroded HLG before die downs (Meltzner et al., 2010). For the corals collected in Yoron, we only used the calculation method of Zachariasen (1998) and Zachariasen et al. (2000) which take into account all HLS and HLG points starting from the first HLS. This method is more appropriate for the living corals of Yoron whose records reflect short-term periods of emergence and submergence rather than successive temporary die downs. As well, the same method was used for the fossil coral of Yoron for which we did not find residual print of die downs (see detailed information in the following section).

\section{Results}

\subsection{Sampling Sites}

Despite its high latitude between $24^{\circ}$ and $31^{\circ} \mathrm{N}$, the Ryukyu archipelago offers plenty of corals due to the warm Kuroshio Current which maintains an average temperature above the minimum temperature required for coral reef survival (Denis et al., 2013; Kan, 2011).

We found plenty of coral microatolls between Okinoerabu and south of Okinawa (Figure 1 and supporting information, Figure S1), all were Porites species, with variable colors from purple to brown-yellow. Their environment varies from open lagoon to emerged reef flat. We observed a large variability in shape among the microatolls that we discovered, from cup-shaped corals indicating submergence at Ie-jima to hat-shaped corals indicating emergence at Yoron (Figure S1).

Based on the geomorphological environment of the microatolls, we decided to focus on four sites: Itoman and Onna (south and west part of Okinawa, respectively), and two sites in the northeastern lagoon of Yoron island (Figure 1 and GPS locations in Table 1).

The site of Itoman corresponds to a pool separated from the open ocean by an emerged platform that stands at about $1.5 \mathrm{~m}$ above the modern HLS recorded by the living microatolls of the area (Figures $2 \mathrm{a}-2 \mathrm{c}$ ). While eroded depressions in the emerged platform are filled by small elevated pools with moated microatolls growing in (total station measurements in green in Figures $2 \mathrm{~b}$ and $2 \mathrm{c}$ ), we found large (around $2.5 \mathrm{~m}$ wide) corals to very large microatolls (overturned microatolls more than $3 \mathrm{~m}$ wide) in the main pool behind the emerged platform (Figures 2a-2d). An artificial channel between the pool and the open ocean was dug in 1907 (Pers. Com from Itoman City Office, Figures 2a and 2b). In the connected pool, we mapped 50 rather flat living coral microatolls that define the modern HLS at an elevation of $-8.31 \pm 0.03 \mathrm{~m}$ (relative to the height of the total station; Figures $2 \mathrm{~b}$ and $2 \mathrm{c}$ ). We sampled two living microatolls we named ITO 1 and ITO 2 (Figures 2b-2f), 1.8 to 2.5 wide and 45 to $65 \mathrm{~cm}$ high (supporting information, Figure S3a-S3b).

As in Itoman, the fringing reef that enclosed the 4-km-long and 1-km-wide Onna site (Figure 3 and supporting information, Figure S2) is protected by an eroded emerged platform standing at about $0.65 \mathrm{~m}$ above the modern HLS (Figures 3a-3c). The platform is more eroded than in Itoman, and three natural channels connect the reef flat to the open ocean (Figure S2). The construction of the port of Maeda between 1984 and 1994 led to the excavation in 1993-1994 of a fourth channel close to our site (personal communication from Onna Fishery Cooperative, Figure S2). In Onna, we mapped around 86 living coral microatolls, which record a modern HLS at $-0.46 \pm 0.06 \mathrm{~m}$ of elevation compared to that of the total station (Figures $3 \mathrm{a}-3 \mathrm{c}$ ). We sampled two living corals we named ONNA 1 and ONNA 2 (Figures $3 \mathrm{~d}$ and 3e). The modern HLS is defined with an accuracy of up to $0.02 \mathrm{~m}$ when measured on individual coral colonies (Figures S3c and S3d). Corals were $2 \mathrm{~m}$ on average, 20 and $50 \mathrm{~cm}$ high and were almost flat or slightly hat-shaped (Figures $3 \mathrm{~d}, 3 \mathrm{e}$, $\mathrm{S} 3 \mathrm{c}$, and $\mathrm{S} 3 \mathrm{~d})$.

We investigated two sites about $500 \mathrm{~m}$ apart (Table 1 and Figure 4) in the wide lagoon of Yoron, described by Yonekura et al. (1994). We targeted the northern site because we discovered very large fossil microatolls of about $8 \mathrm{~m}$ in diameter. We studied smaller living microatolls in the eastern site. The living coral microatolls are $1.5 \mathrm{~m}$ wide and 50 to $70 \mathrm{~cm}$ high (Figures $4 \mathrm{~d}, 4 \mathrm{e}, \mathrm{S} 3 \mathrm{e}$, and S3f) and thus have a higher height to width ratio than the microatolls of Okinawa. The living microatolls display clear rims much more pronounced than in Okinawa (Figures 4d and 4e). We surveyed 15 living microatolls, which mark a mean HLS of $-8.26 \pm 0.07 \mathrm{~m}$ of elevation compared to that of the total station (Figures $4 \mathrm{a}$ and $4 \mathrm{~b}$ ). This modern HLS was slightly higher by around $5 \mathrm{~cm}$ than the older HLS recorded by the large fossils microatolls (Figures $4 \mathrm{f}$ and $4 \mathrm{~g}$ ). As in Okinawa, an emerged platform standing at about $0.8 \mathrm{~m}$ above the modern HLS surrounds our sites (Figure $4 \mathrm{~b}$ ). We 


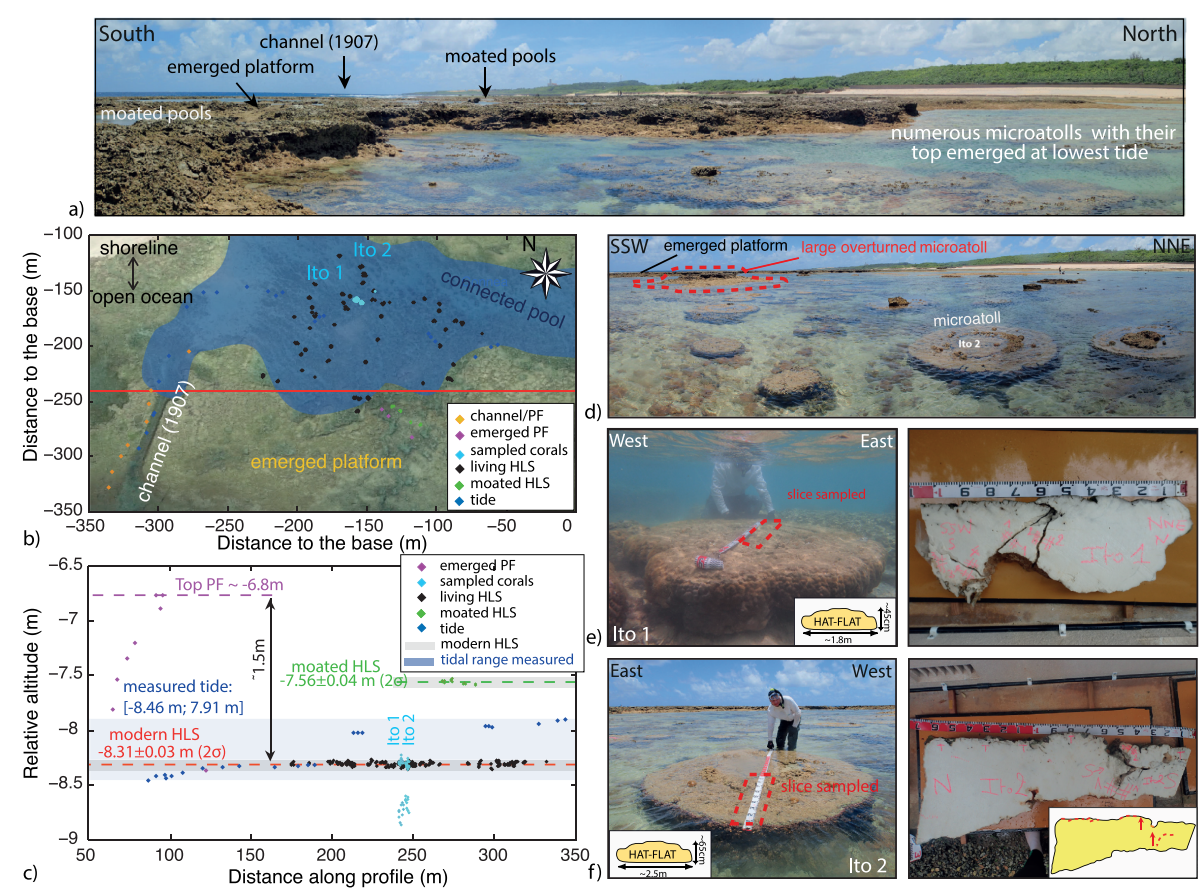

Figure 2. Survey in Itoman, southern Okinawa. (a) Panorama of Itoman site. (b) Map view of the total station survey. Itoman reef setting overlain on a Google Earth screenshot (image taken on 1 April 2015) with total station measurements of the field of microatolls. Sampled microatolls (ITO 1 and ITO 2) are indicated in blue. Red line: location of profile in c, along which all our total station measurements have been projected. PF: Platform. (c) $\mathrm{N} 90^{\circ} \mathrm{E}$ projection of our HLS measurements (location in b). Elevation relative to the height of the total station base. (d) Panorama of the site with Ito 2 microatoll highlighted as well as large overturned microatolls. (e) Pictures of the coral (with its approximate morphology, sketch in the bottom right corner) and the slab ITO 1. (f) Pictures of the coral (with its approximate morphology, sketch in the bottom left corner) and the slab ITO 2. Inset: basic drawing of the thick slab before the thin cutting to highlight the main HLS surfaces recorded by the coral. This step is needed before the thin slicing, as the HLS record can slightly vary in the coral (and thus between thin slices) and also to reconstruct the coral upper surface if small pieces are broken during the slicing. For ITO 2, we identified on the thin slice in Figure 5a, a small missing part between about 1939 and 1950 (highlighted with dashed black line in Figure 5a). All HLS surfaces observed on the slab were also found on the thin slice.

observed that it is more eroded than in Itoman and very discontinuous with wide connections to open ocean, both in the north and in the east (Figure 4c). In Yoron, we collected one large fossil microatoll we named YOR-F1 and two living microatolls we named YOR-1-S1 and YOR-11-S1 (Figures 4d, 4e, 4h, and S3e-S3g).

We observed emerged platforms in the sites we selected and in almost all islands investigated in the central Ryukyu Arc. These platforms were dated mid- to late-Holocene (e.g., Koba et al., 1982; Pirazzoli \& Koba, 1989), and their emergence is being attributed to a combination of eustasy (with a sea level highstand less than $1 \mathrm{~m}$ higher than modern sea-level between 3,500 and 1,700 BP) and regional tectonics (for the terrace distribution and elevation through the whole arc; e.g., Koba et al., 1982). Through the analysis of uplifted marine notches, reefs, beachrocks, and barnacles (survey and ${ }^{14} \mathrm{C}$ dating), Kawana and Pirazzoli (1985) documented geological evidences of a past earthquake in the southern part of Okinawa that would have occurred about 2,400 years ago. Additional studies (mapping and dating) will be needed to demonstrate if the platforms observed on the field may result from coseismic uplift as in southern Okinawa, which is beyond the scope of this paper.

\subsection{RSL Records}

We reconstructed the RSL history over the last century from the living microatolls we sampled in Okinawa and in Yoron and over about three centuries of record from the fossil microatoll of Yoron.

\subsubsection{Itoman, South Okinawa}

The 2.5-m-wide and $0.65-\mathrm{m}$-high ITO 2 microatoll is the largest we have sampled in Itoman (Figures $2 \mathrm{f}$ and $\mathrm{S} 3 \mathrm{~b}$ ). While it is rather flat, the slab stratigraphy reveals that new coral growths have colonized depressions in its center (Figure 5a). 
a)
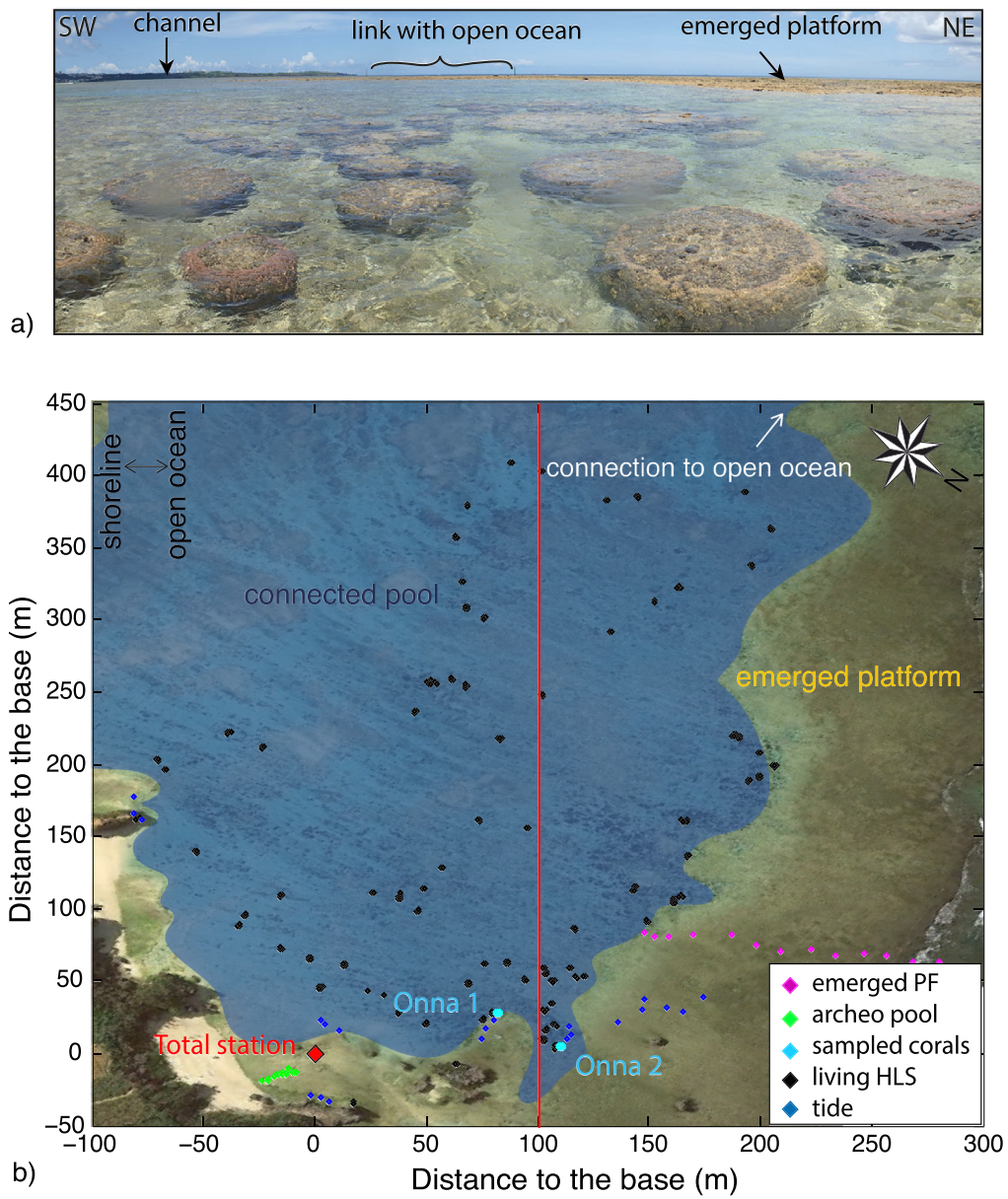

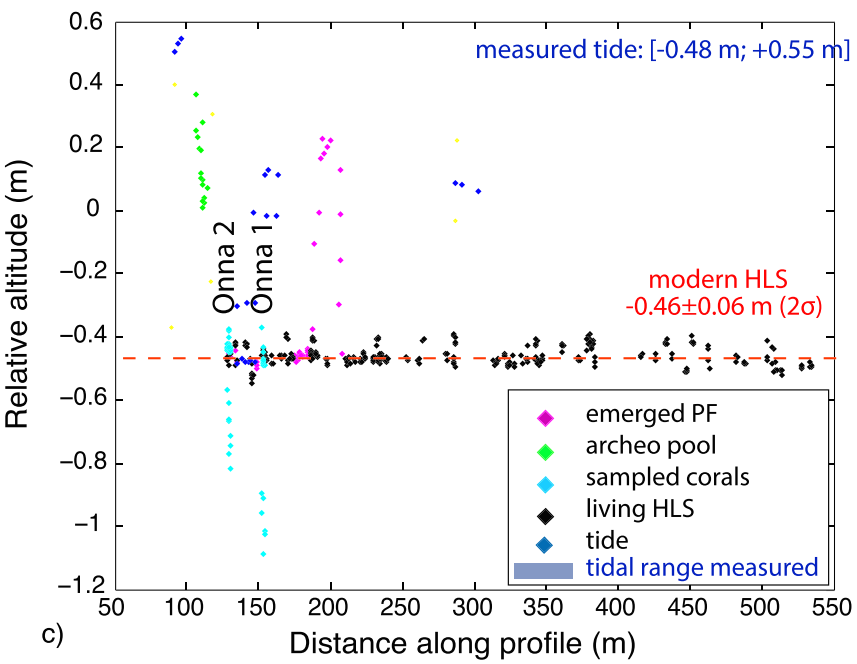

d)
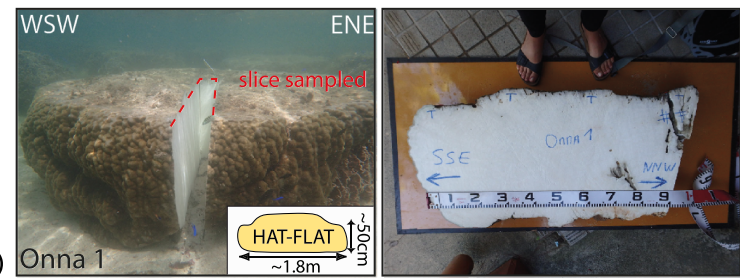

e)
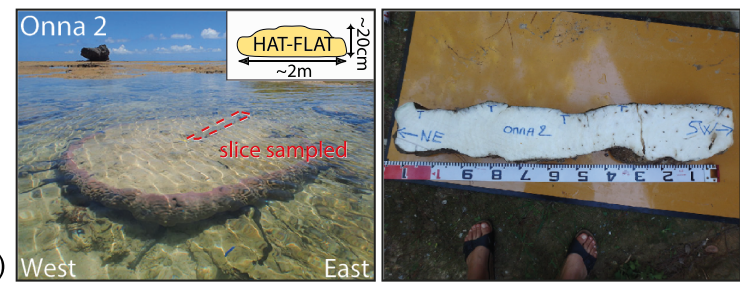

Figure 3. Survey in the site of Onna, western Okinawa. (a) Panorama of Onna site. (b) Map view of the total station survey. Onna reef setting overlain on a Google Earth screenshot (image taken on 1 April 2015) with total station measurements of the field of microatolls. Sampled microatolls (ONNA 1 and ONNA 2) are indicated in blue. Red line: location of profile in b, along which all our total station measurements have been projected. (c) N90 ${ }^{\circ} \mathrm{E}$ projection of our $\mathrm{HLS}$ measurements (location in a). Elevation relative to the height of the total station base. (d) Pictures of the coral (with its approximate morphology, sketch in the bottom right corner) and the slab ONNA 1. (e) Pictures of the coral (with its approximate morphology, sketch in the upper right corner) and the slab ONNA 2.

The coral began to grow radially in 1868 in an unconstrained environment (Figures 5a and 6a). As a result, it developed a ball shape (Figure 5a). It experienced a first HLS drop in 1890 of $5.6 \mathrm{~cm}$ (Figures 5a and 6a). During the following 9 years (between 1890 and 1899), the microatoll recorded a stable HLS before a short period of HLS decrease between 1899 and 1906 (Figures 5a and 6a) that ended with a total large drop of 12.5 $\mathrm{cm}$ of the HLS (Figures 5a and 6a). In between the two HLS drops (1890 and 1906), we calculate that the microatoll recorded a mean emergence rate of $2.5 \pm 1.1 \mathrm{~mm} /$ year (blue line on that time period in Figure 6a). The emergence may have been continuous or made of multiple small RSL drops, which could have been smoothed by erosion.

Between 1868 and 1906, ITO 2 was growing in an enclosed pool that was not freely connected to the open ocean until an artificial channel was dug in 1907 (oral informations from Itoman City Office, Figures 2a and $2 \mathrm{~b}$ ). As this coral was moated, it likely recorded the sea-level variations in the pool rather than the true RSL changes in the open ocean. The total station measurements indicate that, at the time of the survey in 2016, the surface of ITO 2 was about $1.5 \mathrm{~m}$ below the top of the emerged platform, which acted as a barrier (Figure 2c). In 1890, after reaching a first HLS, the top of the coral was about $15 \mathrm{~cm}$ below its level in 2016 (Figure 5a) and thus about $1.65 \mathrm{~m}$ below the top of the platform. From the tide predictions for the Okinawa tide gauge (supporting information, Figure S4), we inferred an average tidal range of $2 \mathrm{~m}$, and comparison with our total station measurement highlights that the top of the platform is only slightly below the highest tide (Figure S4). By considering that the tide curve did not change since 1890, which is a 

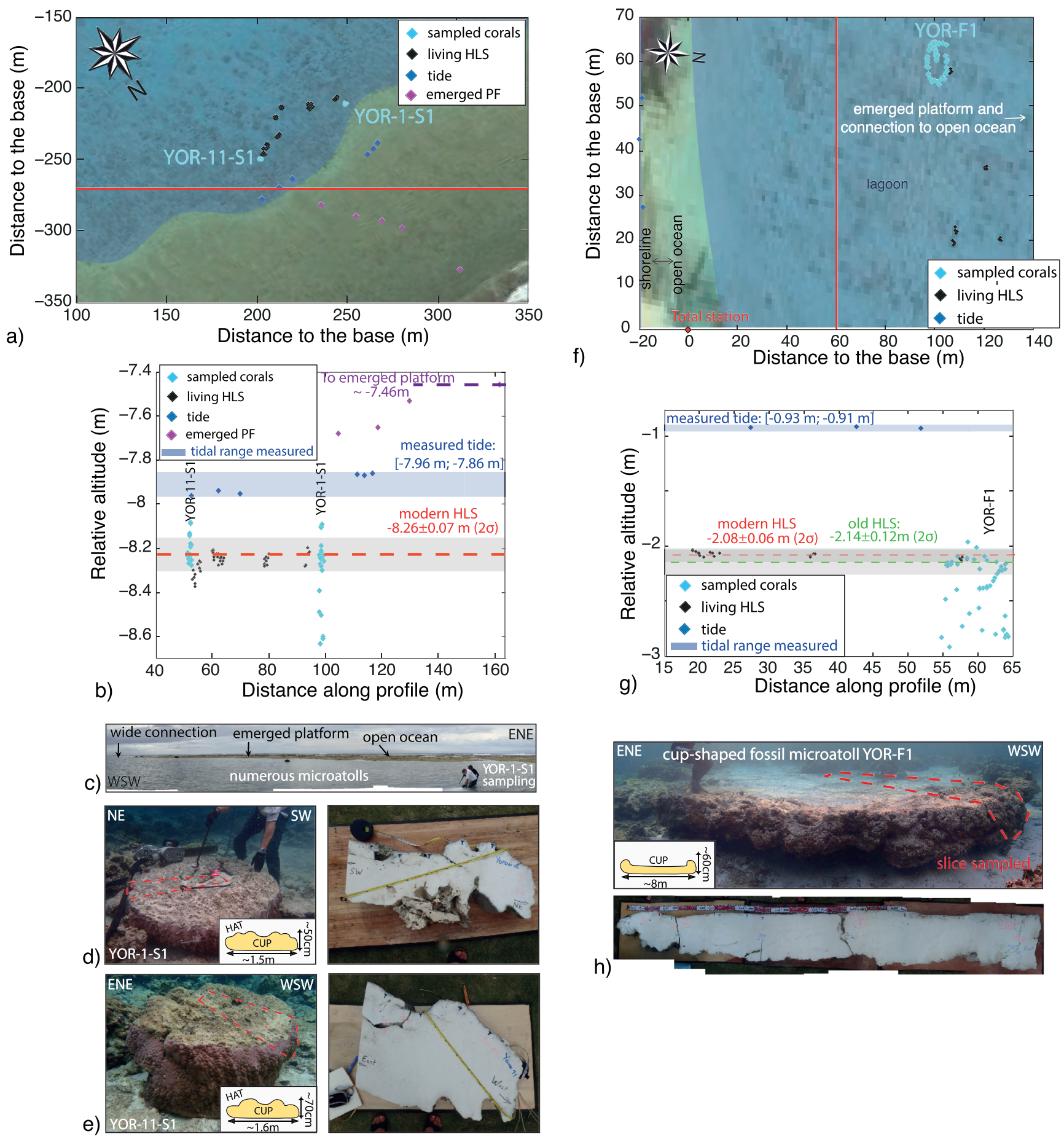

Figure 4. Survey in Yoron. (a) Map view of the total station survey for the first site. Yoron reef setting overlain on a Google Earth screenshot (image taken on 1 April 2015) with total station measurements of the field of microatolls. Sampled microatolls (YOR-1-S1 and YOR-11-S1) are indicated in blue. Red line: location of profile in b, along which all our total station measurements have been projected. (b) $\mathrm{N} 90^{\circ} \mathrm{E}$ projection of our HLS measurements (location in a). Elevation relative to the height of the total station base. (c) Panorama of the first site of Yoron. (d) Pictures of the coral (with its approximate morphology, sketch in the bottom right corner) and the slab YOR-1-S1. (e) Pictures of the coral (with its approximate morphology, sketch in the bottom right corner) and the slab YOR-11-S1. (f) Map view of the total station survey for the second site. Yoron reef setting overlain on a Google Earth screenshot (image taken on 1 April 2015) with total station measurements of the field of microatolls. The sampled microatoll YOR-F1 is indicated in blue. Red line: location of profile in g, along which all our total station measurements have been projected. (g) $\mathrm{N} 90^{\circ} \mathrm{E}$ projection of our HLS measurements (location in f). Elevation relative to the height of the total station base. (h) Panorama of the fossil microatoll (with its approximate morphology, sketch in the bottom left corner) and picture of the coral slab YOR-F1. 
a) ITO 2
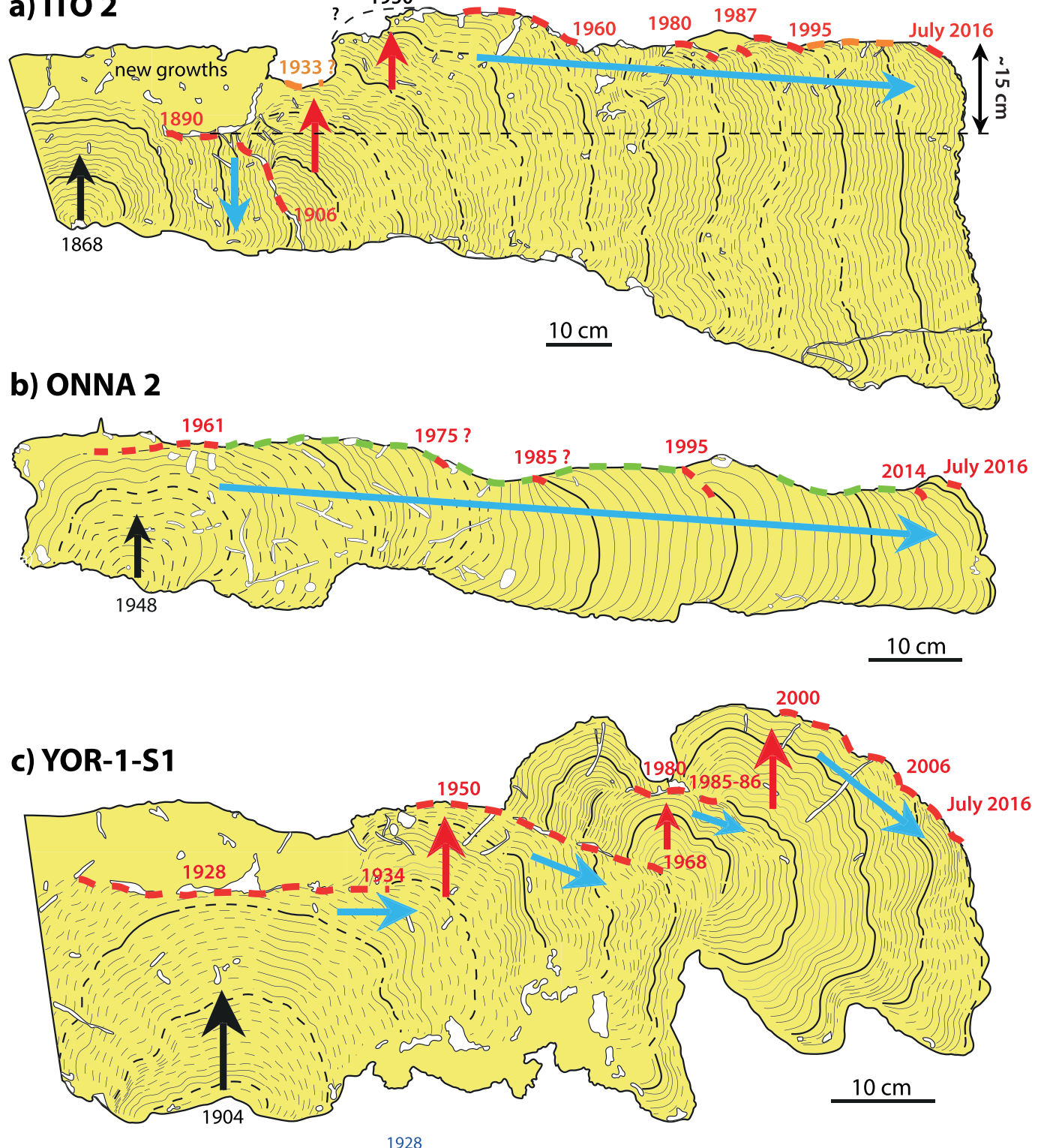

d) YOR-F1

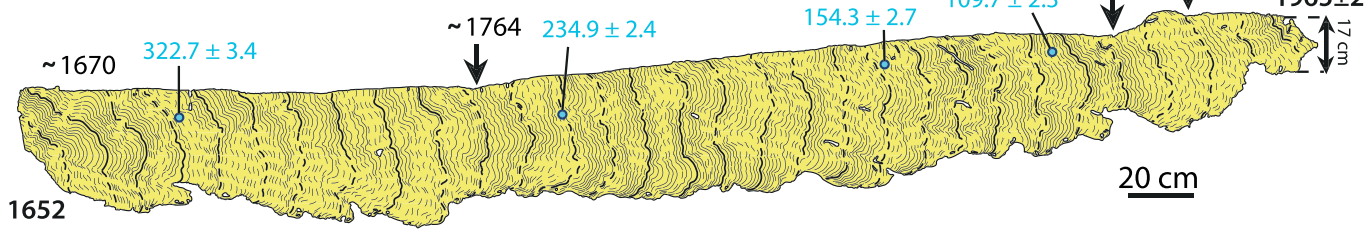

Figure 5. Coral stratigraphy of the longest coral records in the central Ryukyu Arc. (a) ITO 2 slab stratigraphy. In yellow: coral skeleton with holes in white. Annual growth bands in black with thicker bands every 10 years. Dashed black lines: unclear bands. As the external ring dates to July 2016, each growth band corresponds to the middle of the year. Dashed red lines with corresponding dates: die downs. Black arrow: coral unconstrained upward growth before reaching a first HLS. Blue arrows: emergence trend (the first that occured in 1906 is a sudden RSL drop related to the channel opening that connected the pool to the open ocean). Red arrow: submergence trend (sudden or gradual). (b) Slab stratigraphy of ONNA 2. Symbols and dates as in (a). (c) Slab stratigraphy of YOR-1-S1. Symbols and dates as in (a). (d) Slab stratigraphy of YOR-F1. Symbols and dates as in (a). Blue dots (with corresponding dates): location of the U-Th dating (results in Table 2). Black arrows with corresponding number: possible changes in the coral record. 

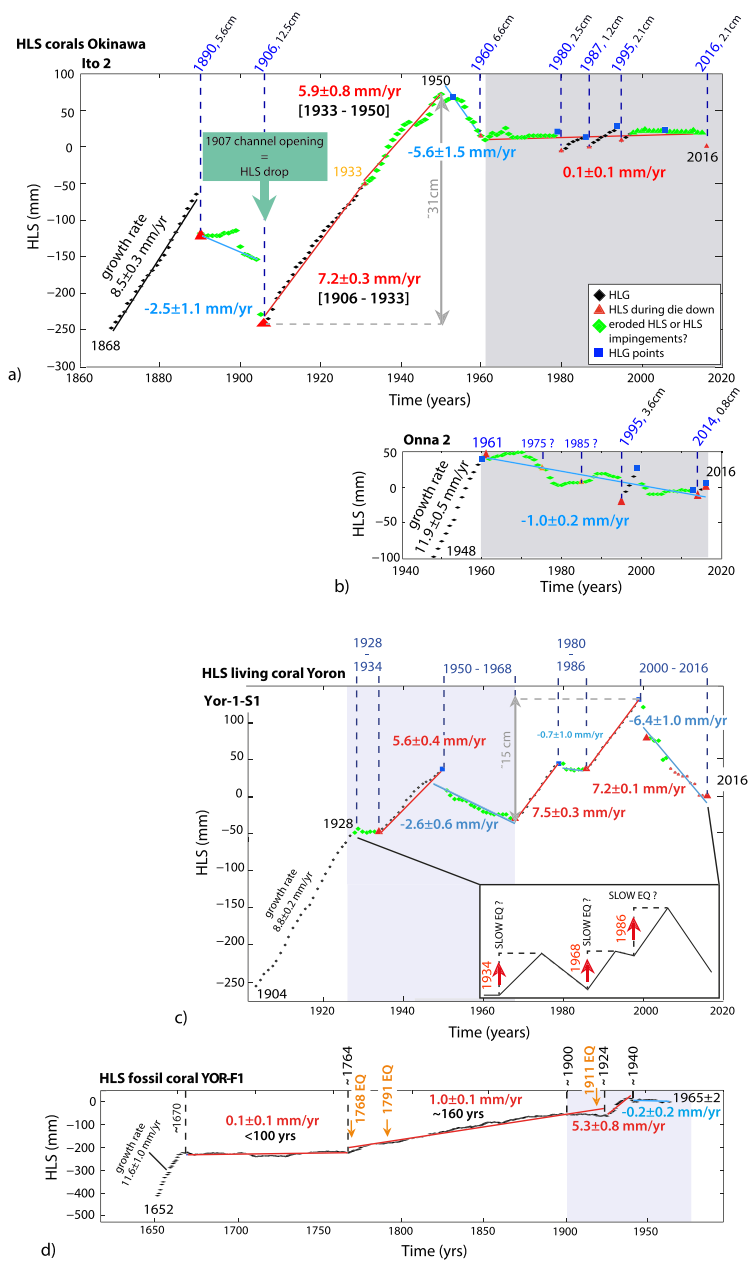

Figure 6. HLS curves of the longest coral records in the central Ryukyu Arc. (a) ITO 2 HLS curve. From the drawing, we plot the upper altitude of each growth band. The reference altitude (0) is the elevation of the 2016 growth band. A HLG data (black diamond) corresponds to complete growth band when the coral did not reach its theoretical HLS (e.g., Zachariasen et al., 1999, 2000) while an HLS data (red triangle) refer to truncated growth band that follow a die down (Meltzner et al., 2010). HLG points correspond to noneroded HLG years recorded before a die down and are highlighted with blue squares. Truncated growth bands for which we have difficulty to decipher between erosion and RSL changes are named eroded HLS or HLS impingements and are highlighted with green diamonds. Dashed blue lines: die down events with dates indicated in blue and amplitudes of the relative sea-level drops in black. Red and blue straight lines: Submergence and emergence rates (given in millimeter per year with $2 \sigma$ uncertainty) calculated by linear regression with all points starting from the first HLS point (e.g., Zachariasen et al., 2000). The upward coral growth rate at the beginning of the coral growth (given in millimeterm per year with $2 \sigma$ uncertainty) is calculated with linear regression. Green rectangle with arrow: major HLS drop around 1906 due to the connection to the open ocean through the construction and the opening of a channel in 1907 (personal communication from Itoman City Office). Double gray arrows with number indicated and dashed gray line: estimate of the RSL increase between 1906 and 1950 recorded by ITO 2. (b) ONNA 2 HLS curve. Symbols, rates, and dates as in (a). (c) YOR-1-S1 1 HLS curve. Symbols, rates, and dates as in (a). Double gray arrows with number indicated and dashed gray line: estimate of the RSL increase over the last 48 years recorded by YOR-1-S1. Inset: schematic record with sudden/gradual submergence events around 1934, 1968 and 1986 that could be due to slow earthquakes (see main text). (d) YOR-F1 HLS curve. Symbols, rates, and dates as in (a). Dashed black lines with corresponding number: possible changes in the coral record. Orange arrows: major reported earthquakes. Gray rectangles: shared record between ITO 2 and ONNA 2. Blue rectangles: shared record between YOR-1-S1 and YOR-F1. 
a) ITO 1
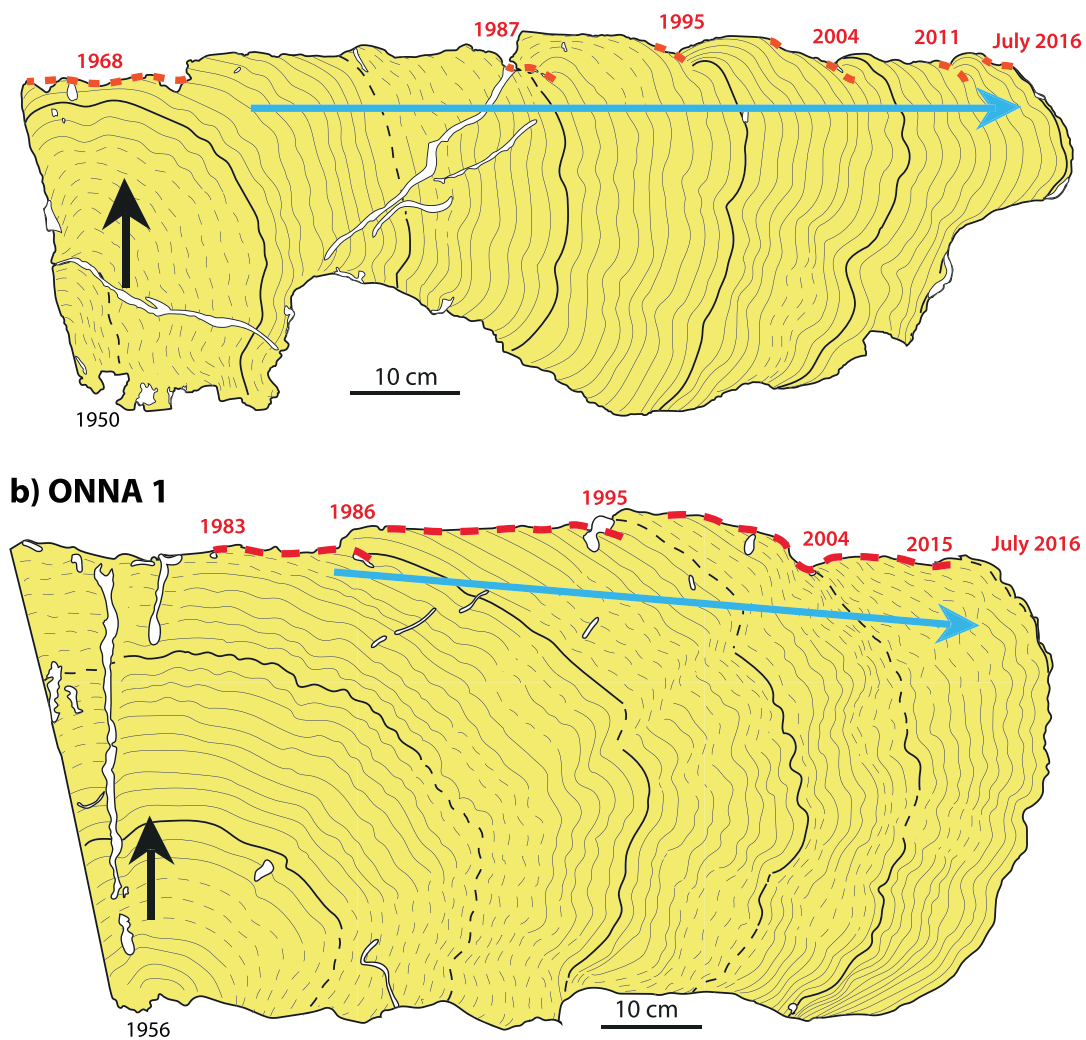

c) YOR-11-S1

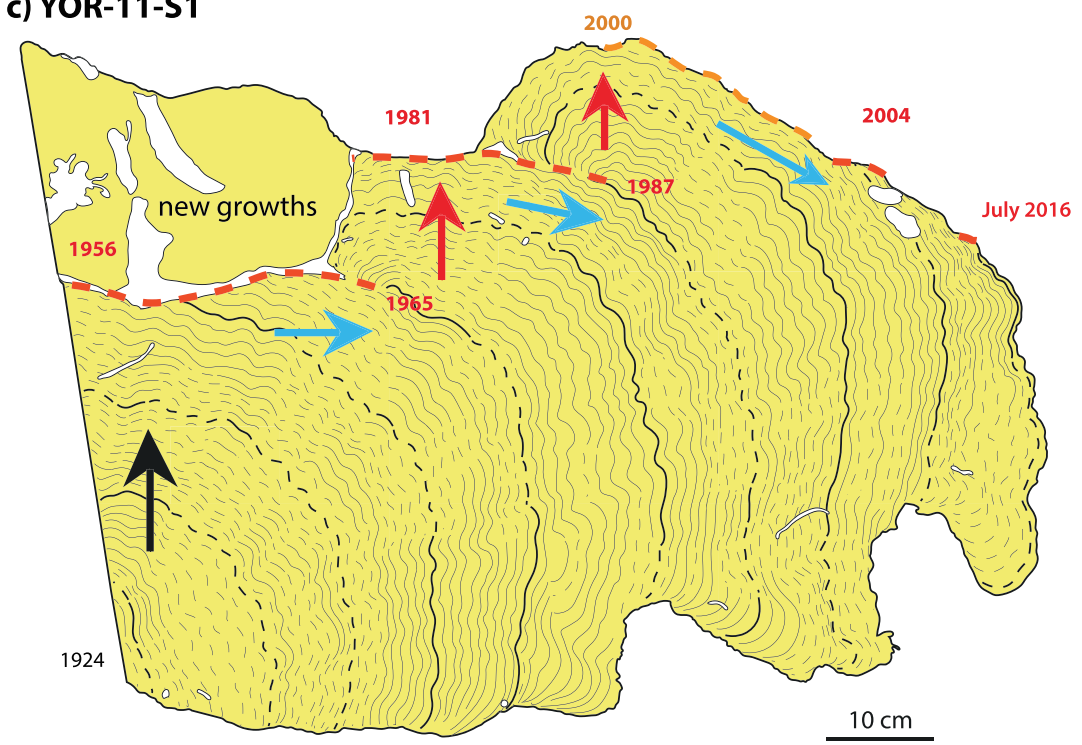

Figure 7. Coral stratigraphy for the other coral slabs sampled in the central Ryukyu Arc. Symbols and dates as in Figure 5. (a) ITO 1 slab stratigraphy. (b) ONNA 1 slab stratigraphy. (c) YOR-11-S1 slab stratigraphy.

reasonable assumption on such a short timescale, ITO 2 only missed a small part of the tidal cycle (tens of centimeters at most) before the channel opening. This is attested by the sea-level drop of $12.5 \mathrm{~cm}$ recorded around 1906 at the channel opening (Figures 5a, 6a, and supporting information, Figure S5). This value corresponds to the difference in elevation between the lowest tide recorded by microatolls connected to the open ocean and those that were located in the previously enclosed pool (Figure S5). The corals in the pool likely did not record the lowest yearly levels of the tidal cycle and the extreme climatic die downs. However, 


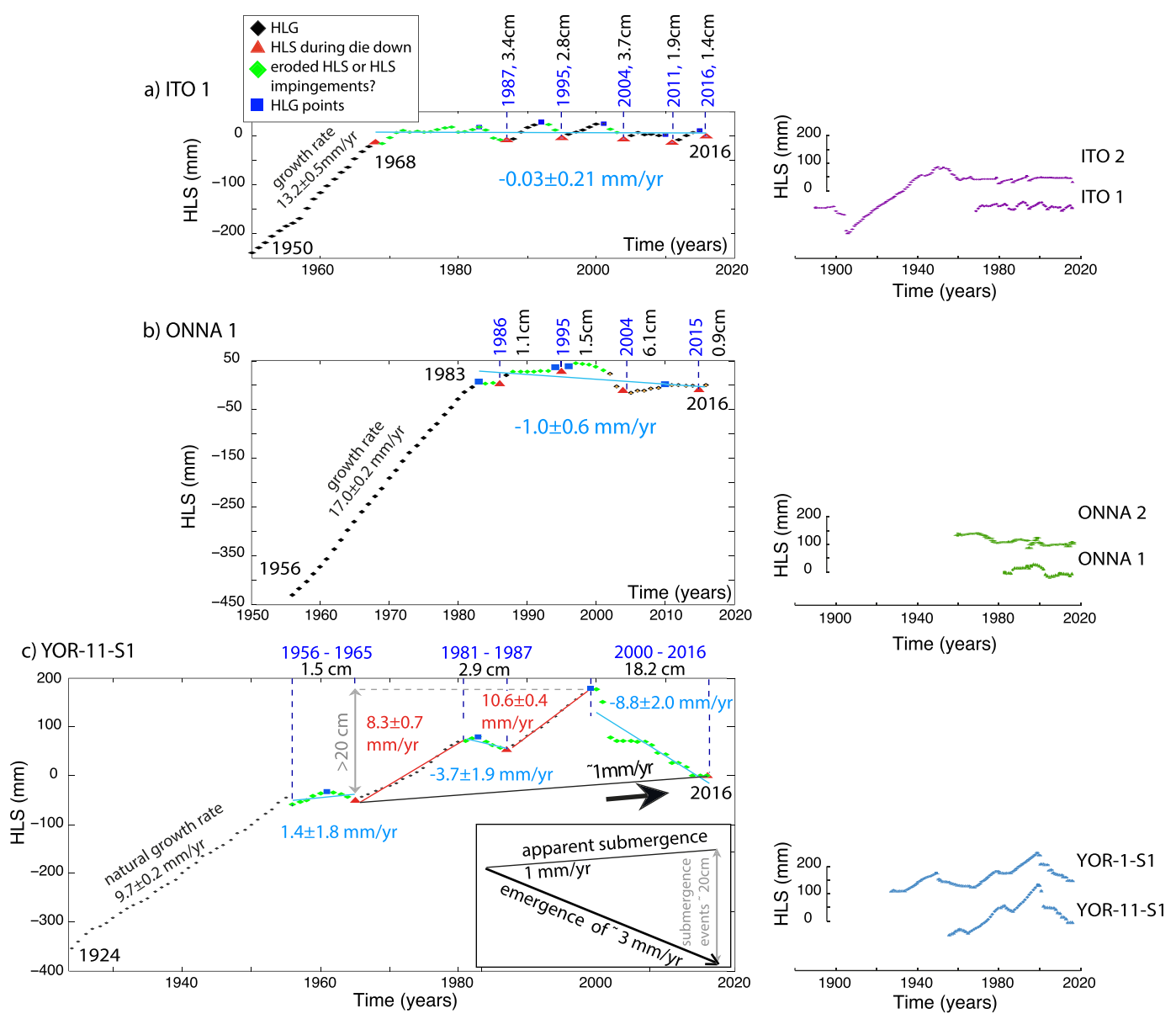

Figure 8. HLS curves for the other coral slabs sampled in the central Ryukyu Arc. Symbols and dates as in Figure 6. (a) ITO 1 HLS curve (left), both ITO 1 and ITO 2 HLS curves once the corals reached their first HLS (right). (b) ONNA 1 HLS curve (left), both ONNA 1 and ONNA 2 HLS curves (right). (c) YOR-11-S1 HLS curve (left), both YOR-1-S1 and YOR-11-S1 HLS curves (right). Double gray arrows with number indicated and dashed gray line: estimate of the RSL increase over the last 51 years recorded by YOR-11-S1. Inset: graphic view of the calculation of the net emergence signal recorded by the coral, after the subtraction of the submergence events to the apparent submergence trend (calculated through the whole coral signal that combines periods of submergence and periods of emergence).

as the upper surface of the coral before 1906 was not limited by the top of the emerged platform (as it could be in theory for fully impermeable moated pool, Smithers, 2011), it was able to track the sudden permanent changes in relative sea level or continuous variations over several years in the pool, at a slightly higher level than in the open ocean.

Between 1906 and 1950, the coral recorded a period of rapid upward columnar growth (Figures 2f, 5a, and 6a) that might be divided in two parts (between 1906 and 1933 and between 1933 and 1950) because we observed an HLS impingement around 1933 (Figures 2f, 5a, and 6a). The coral has grown radially in an unconstrained environment at a rate of about $7.2 \pm 0.3 \mathrm{~mm} /$ year (similar to the coral's natural growth rate established between 1868 and 1890) until it reached an HLS in 1933 (Figure 6a). Then, a second RSL increase at slightly slower rate of $5.9 \pm 0.8 \mathrm{~mm} /$ year has been recorded until 1950 (Figure 6a). During that period, the coral might have been close to its HLS according to the lower upward growth rate and the shape of the growth bands that seems to flatten the coral's surface with a decrease of the growth band thickness from the side to the top the coral (Figures 5a and 6a). The two RSL increases were sudden and/or gradual at faster rate than the coral's natural growth rate (at least for the period 1906-1933). In total, ITO 2 recorded about $31 \mathrm{~cm}$ of RSL increase between 1906 and 1950 (Figure 6a).

The later period was followed by a permanent RSL drop of $6.6 \mathrm{~cm}$ that could have started around 1950 (Figures 5a and 6a). Between 1960 and July 2016, the coral mainly grew laterally very close to its HLS and 
was frequently impinged by centimetric RSL drops of 2.5, 1.2, 2.1, and $2.1 \mathrm{~cm}$ in 1980, 1987, 1995, and 2016, respectively (Figures 5a and 6a). Whereas the die downs of 1980, 1987, and 1995 were followed by a slight upward growth, the drop of 1960 was permanent and marked the beginning of the main outward growth of the coral (Figures 5a and 6a). We calculated an emergence trend of $5.6 \pm 1.5 \mathrm{~mm} /$ year between 1950 and 1960 followed by a stability of the relative sea level until 2016 (rate of $0.1 \pm 0.1 \mathrm{~mm} /$ year; Figure 6a).

The second coral we sampled in the site (ITO 1) is also flat, with height to width ratio equal to that of ITO 2 (Figures 2e and S3a). It recorded a shorter RSL history, however, because it began to grow in 1950 (Figures 7a and 8a). It reached its first HLS in 1968 (Figures 7a and 8a) and mainly grew outward. As ITO 2, it recorded centimetric die downs in 1987, 1995, and 2016 (3.4, 2.8, and $1.4 \mathrm{~cm}$, respectively) as well as additional drops in 2004 and 2011 (3.7 and $1.9 \mathrm{~cm}$, respectively, Figures 7a and 8a). Overall, ITO 1 recorded a stability of the relative sea level (rate of $-0.03 \pm 0.21 \mathrm{~mm} /$ year), as ITO 2 did over the same period (Figures $7 \mathrm{a}$ and $8 \mathrm{a}$ ).

At a first order, records from both corals are in good agreement despite slight differences in amplitudes of die downs and in the number of HLS impingements. These small stratigraphic differences reflect the small (few centimeters) spatial fluctuations of the modern HLS at the scale of the entire site and reveal the coral's natural variability within a reef in response to RSL changes (Weil-Accardo, Feuillet, Jacques, Deschamps, Beauducel, et al., 2016; Weil-Accardo, Feuillet, Jacques, Deschamps, Saurel, et al., 2016).

\subsubsection{Onna, West Okinawa}

The longest record in Onna is provided by the 2-m-wide and 20-cm-thick ONNA 2 microatoll (Figures 3e and S3d). The ONNA 1 coral is twice as thick than ONNA 2, because it grew in a deeper part of the reef flat, and is slightly smaller (Figures $3 \mathrm{~d}$ and S3c). They are both flat to slightly hat-shaped (Figures 3d, 3e, S3c, and S3d), typical of the other hundreds of corals we surveyed (Figures 3a-3c).

ONNA 2 began to grow in 1948 and reached its first HLS in 1961 (Figures 5b and 6b). It then mainly grew outward until 2016 and experienced at least two die downs in 1995 and 2014 of 3.6 and $0.8 \mathrm{~cm}$ of amplitude, respectively (Figures 5b and 6b). We possibly missed other die downs (likely in 1975 and 1985) whose residual prints could have been erased by a slight erosion (Figure 5b). The morphology of this coral characterized by a flat surface and a small height implies that ONNA 2 grew in a very shallow environment since 1948. We calculated an emergence rate of about $1 \mathrm{~mm}$ /year over the last 55 years (Figure 6b).

ONNA 1 recorded a similar history with an emergence rate of $1 \mathrm{~mm} /$ year over the last 33 years (Figures $7 \mathrm{~b}$ and 8 b). It also recorded the die downs of 1995 and 2015 with amplitude of 1.5 and $0.9 \mathrm{~cm}$, respectively (Figures $7 \mathrm{~b}$ and $8 \mathrm{~b}$ ). Its surface being probably less eroded than that of ONNA 2, additional die downs that occurred in 1986 and 2004 with amplitude of 1.1 and $6.1 \mathrm{~cm}$, respectively (Figures $7 \mathrm{~b}$ and 8b), were preserved. 3.2.3. Yoron

In Yoron, the two living corals we sampled in the first site are $1.5 \mathrm{~m}$ wide and between 50 and $70 \mathrm{~cm}$ thick (Figures 4d, 4e, S3e, and S3f). They both display a complex upper surface with clear rims (Figures 4d and 4e). The modern HLS being more than $10 \mathrm{~cm}$ lower than the top of the corals (Figures $6 \mathrm{c}, 8 \mathrm{c}$, S3e, and S3f), we describe them as hat-shaped microatolls (Figure S1).

The coral YOR-1-S1 provide the longest RSL record (Figures 5c and 6c). It began to grow in 1904 and reached a first HLS in 1928 (Figures 5c and 6c). Between 1928 and 1934, the coral grew outward close to its HLS in a stable RSL environment (Figures 5c and 6c). From 1934 until 1950, it grew upward at rate of $5.6 \pm 0.4 \mathrm{~mm} /$ year, catching-up a sudden or gradual RSL increase (Figures 5c and 6c). YOR-1-S1 kept recording alternations of periods of stable to RSL decrease (between 1950 and 1968, 1980 and 1986, 2000 and 2016) and periods of RSL rise either sudden or gradual (between 1934 and 1950, 1968 and 1980, 1986 and 2000) (Figures 5c and 6c).

The neighbouring coral YOR-11-S1 recorded a very similar RSL signal. After 32 years of unlimited upward growth at rate of $9.7 \pm 0.2 \mathrm{~mm} /$ year, the coral reached its first HLS in 1956 and then recorded periods of stable RSL to RSL decrease characterized by several HLS impingements (between 1956 and 1965, 1981 and 1987, 2000 and 2016), alternating with periods of unconstrained upward growth in a context of a sudden or high-rate submergence (between 1965 and 1981, and from 1987 to 2000, Figures 7c and 8c).

A striking observation is that for both corals, the value of the RSL increase (e.g., the difference between the HLS at the beginning and at the end of the rapid upward growth period) is almost always the same from a period to another one. It ranges between about 8 and $13 \mathrm{~cm}$ (around $9 \mathrm{~cm}$ in 1934, $13 \mathrm{~cm}$ in 1965, or $8 \mathrm{~cm}$ in 1968 and $10 \mathrm{~cm}$ in 1986 or $12 \mathrm{~cm}$ in 1987, Figures 5c, 6c, 7c, and 8c). 
Table 3

Raw Submergence (in Red) and Emergence (in Blue) Rates in Millimeter per Year With $2 \sigma$ Uncertainty, Calculated With Different Methods of Meltzner et al. (2010), Zachariasen (1998), and Zachariasen et al. (2000)

\begin{tabular}{|c|c|c|c|}
\hline Sample name & Time period & $\begin{array}{l}\text { Raw RSL rate } \\
\mathrm{mm} / \mathrm{year}\end{array}$ & $\begin{array}{l}\text { Corrected rate since } 1950 \\
\mathrm{~mm} / \text { year }\end{array}$ \\
\hline ITO 2 & [1890-1906] & $-2.5 \pm 1.1$ & \\
\hline ITO 2 & [1906-1933]* & MIN $7.2 \pm 0.3$ & \\
\hline ITO 2 & {$[1933-1950]^{\mathrm{a}}$} & $5.9 \pm 0.8$ & \\
\hline ITO 2 & [1950-1960] & $-5.6 \pm 1.5$ & $-8.6 \pm 1.8$ \\
\hline ITO 2 & [1960-2016] & $0.1 \pm 0.1$ & $-2.9 \pm 1.0$ \\
\hline ITO 1 & [1968-2016] & $-0.03 \pm 0.21$ & $-3.0 \pm 1.0$ \\
\hline ONNA 2 & [1961-2016] & $-1.0 \pm 0.2$ & $-4.0 \pm 1.0$ \\
\hline ONNA 1 & [1983-2016] & $-1.0 \pm 0.6$ & $-4.0 \pm 1.2$ \\
\hline Naha tide gauge - GPS ${ }^{b}$ & [2000-2014] & 2.15 & $-0.53 \pm 0.35$ \\
\hline YOR-1-S1 ${ }^{\mathrm{c}}$ & [1928-1934] & $\approx 0$ & \\
\hline YOR-1-S1 & [1934-1950]* & MIN $5.6 \pm 0.4$ & \\
\hline YOR-1-S1 & [1950-1968] & $-2.6 \pm 0.6$ & $-5.6 \pm 1.2$ \\
\hline YOR-1-S1 & [1968-1980]* & MIN $7.5 \pm 0.3$ & $\mathrm{MIN}+4.5 \pm 1.0$ \\
\hline YOR-1-S1 & [1980-1986] & $-0.7 \pm 1.1$ & $-3.7 \pm 1.5$ \\
\hline YOR-1-S1 & [1986-2000]* & MIN $7.2 \pm 0.1$ & $\mathrm{MIN}+4.2 \pm 1.0$ \\
\hline YOR-1-S1 & [2000-2016] & $-6.4 \pm 1.0$ & $-9.4 \pm 1.4$ \\
\hline YOR-1-S1 ${ }^{\mathrm{d}}$ & [1968-2016] & $\approx 0.6$ & -2 \\
\hline YOR-1-S1 ${ }^{\mathrm{e}}$ & [1968-2016] & $\approx-2.5$ & -5.5 \\
\hline YOR-11-S1 ${ }^{\mathrm{f}}$ & [1956-1965] & $1.4 \pm 1.8$ & $-1.6 \pm 2.1$ \\
\hline YOR-11-S1 & {$[1965-1981]^{*}$} & MIN $8.3 \pm 0.7$ & $\mathrm{MIN}+5.3 \pm 1.2$ \\
\hline YOR-11-S1 & [1981-1987] & $-3.7 \pm 1.9$ & $-6.7 \pm 2.2$ \\
\hline YOR-11-S1 & [1987-2000]* & MIN $10.6 \pm 0.4$ & $\mathrm{MIN}+7.6 \pm 1.1$ \\
\hline YOR-11-S1 & [2000-2016] & $-8.8 \pm 2.0$ & $-11.8 \pm 2.2$ \\
\hline YOR-11-S1g & [1965-2016] & $\approx 1$ & -2 \\
\hline YOR-11-S1 ${ }^{\mathrm{h}}$ & [1965-2016] & $\approx-3$ & -6 \\
\hline YOR-F1 & $\approx[1670-1764]$ & $0.08 \pm 0.04$ & \\
\hline YOR-F1 & $\approx[1764-1924]$ & $1.04 \pm 0.04$ & \\
\hline YOR-F1 & $\approx[1924-1940]^{*}$ & MIN $5.3 \pm 0.8$ & \\
\hline YOR-F1 & $\approx[1940-1965]$ & $-0.2 \pm 0.2$ & $-3.2 \pm 1.0$ \\
\hline
\end{tabular}

Note. For periods of RSL stability (according to geomorphologic observations), the rate is written in black. Since all calculation methods give very similar results, we choose to rather use the calculation method of (Zachariasen, 1998; Zachariasen et al., 2000) and considered all HLG and HLS points starting from the first HLS in the linear regression. This method is also more appropriate for corals from Yoron for which we calculate rates on shorter time periods than the whole record duration due to major changes in growth pattern. The last column corresponds to the RSL rate corrected from $3 \pm 1 \mathrm{~mm} /$ year of regional sea-level rise since 1950 (see main text). We use asterisks to highlight periods of sudden or gradual (at a rate faster than the growth rate) submergence during which the coral upward growth is unconstrained and for which we can only calculate minimum submergence rates (see main text).

${ }^{a}$ ITO 2: period during which growth bands seem to flatten the surface with a decrease of the band thickness from the side to the top of the coral, implying a proximity to the coral HLS and thus that ITO 2 likely recorded a gradual submergence during that period. ${ }^{b}$ Naha tide gauge co-located with a GPS allows to access to both tectonic motion and absolute sea-level trend (e.g., Wöppelmann \& Marcos, 2016). The two values for columns three and four are from http://www.sonel.org/. ${ }^{c}$ YOR-1-S1: this part of the signal corresponds to a period during which the coral was close to its HLS (Figures 5c, 6c, and 9). ${ }^{\text {d} Y O R-1-S 1: ~ g r a p h i c ~ e s t i m a t e s ~ o f ~ t h e ~ a p p a r e n t ~ s u b m e r g e n c e ~ t r e n d s ~ r e c o r d e d ~ s i n c e ~} 1968$. ' $Y O R-1-S 1:$ Attempts to estimate rates of emergence after removing the effect of the last two submergence periods

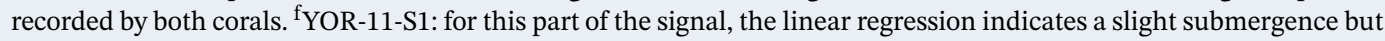
the stratigraphic analysis of the slab rather suggests a period of RSL stability with the coral upper surface close to its HLS (Figures 7c and 8c) which is why we highlight the raw rate in black. 9YOR-11-S1: graphic estimates of the apparent submergence trends recorded since 1965. hYOR-11-S1: Attempts to estimate rates of emergence after removing the effect of the last two submergence periods recorded by both corals. 


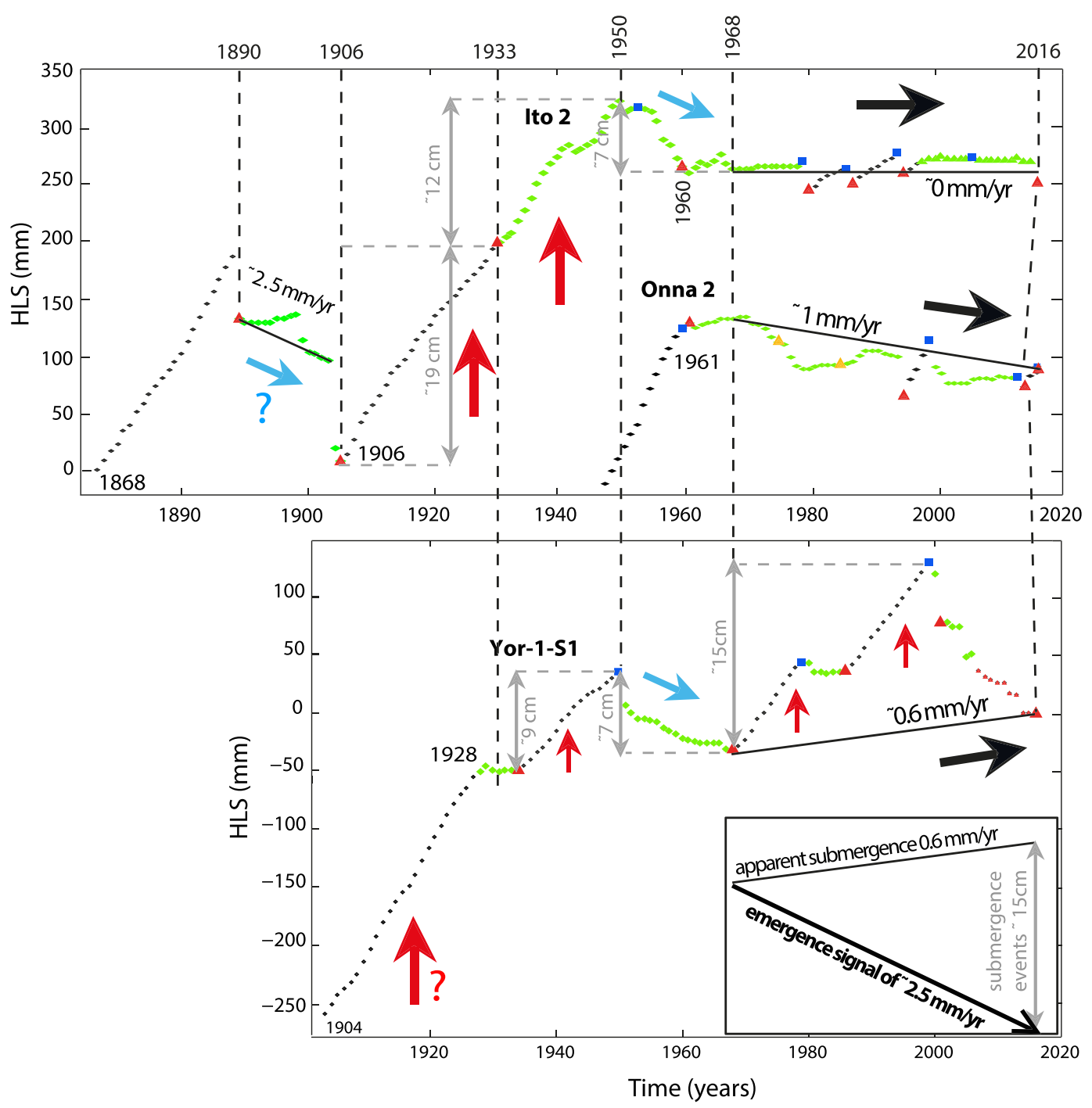

Figure 9. Comparison of the three longest living coral records for each site. Dashed black lines: attempt of correlation between records. Red arrows: submergence events (sudden or gradual). Blue arrows: likely permanent RSL drops with one that would have started around 1950. Black arrows: average RSL trend over about the last 50 years that slightly varies from slight emergence in Itoman and Onna to slight submergence in Yoron. Double gray arrows with number indicated and dashed gray lines: estimates of the RSL increases recorded between 1906 and 1950 by ITO 2, recorded between 1934 and 1950 by YOR-1-S1, recorded over the last 48 years recorded by YOR-1-S1 (see text) and estimate of the RSL drop recorded by ITO 2 and YOR-1-S1 between 1950 and 1968. Inset in YOR-1-S1 HLS: graphic view of the calculation of the net emergence signal recorded by the coral, after the subtraction of the submergence events to the apparent submergence trend (calculated through the whole coral signal that combines periods of submergence and periods of emergence).

The fossil microatoll YOR-F1 was sampled in the second site of Yoron (Figure 4f). It is almost $8 \mathrm{~m}$ wide and $60 \mathrm{~cm}$ high and displays a cup morphology indicating submergence (Figures $4 \mathrm{~h}$ and S3g). We performed U-Th dating along the slab (Table 2 and Figure 5d). According to the four U-Th ages, which are in good agreement with each other and the visual counting of the growth bands, this coral would have died about 50 years ago around $1965 \pm 2$ (Figures 5d and 6d). The inner part of the coral, between the first HLS reached around 1670 and 1924, was smoothed by erosion, and we could not find any residual imprints of past die downs (Figure 5d). It is however clear that the coral recorded a slow RSL increase reaching at most about $1 \mathrm{~mm} /$ year during this period of about 260 years with possible changes in rate around 1764 and 1900 (Figures 5d and $6 \mathrm{~d})$. The coral is characterized by a well-marked external younger rim, which is higher than the inner part (Figures $4 \mathrm{~h}$ and $5 \mathrm{~d}$ ). This implies a major acceleration of the submergence with a rate increasing from about 
$1 \mathrm{~mm} /$ year to about $5 \mathrm{~mm} /$ year between 1924 and 1940 (Figure 6d). After 1940, the coral recorded a stable RSL until it died (Figures 5d and 6d).

We observed another fossil coral of similar size and exhibiting the same morphology (with a central plateau and a well-marked external rim) close to YOR-F1. This indicates that the whole site recorded the same RSL history and that the cup shape of the fossil microatolls is not the result of erosion. The fossil coral YOR-F1, being very young, underwent erosion only very recently. This erosion likely smoothed only the upper surface of the central plateau, and erased the subtle marks of small centimetric die downs whose amplitude ranges in average between 1 and $3 \mathrm{~cm}$ according to what we observed on other living corals. We are thus confident that the two main changes in the morphology of the coral (around 1764 and within the last decades before the coral death) are reliable marks of past RSL changes.

Moreover, the HLS record of YOR-F1 and the longest HLS record of the living coral YOR-1-S1 are similar in both timing and rate changes over the same period, with a time delay of a few years due to uncertainties on U-Th dating and growth band counting (Figures $6 \mathrm{c}$ and $6 \mathrm{~d}$ with shared records highlighted with blue rectangles).

\section{RSL Changes Pattern at Regional Scale}

\subsection{Comparison Between Onna, Itoman, and Yoron RSL Records}

We attempted to compare the RSL record in the three sites we investigated. The longest HLS curves are presented on Figure 9, and all the RSL rates are in Table 3. Since the HLS records between the two living corals sampled at the same site are in good agreement with each other, we will mainly focus on the longest RSL records of each site in the following section.

The largest signal deduced from the microatolls we collected is the $\approx 31 \mathrm{~cm}$ of submergence recorded by the coral ITO 2 in Itoman between 1906 and 1950 (Figure 9). The submergence might be separated in two phases: between 1906 and 1933 and between 1933 and 1950. From 1906 to 1933, the coral grew freely upward by $19 \mathrm{~cm}$ at rate of about $7 \mathrm{~mm} /$ year (close to the coral's natural growth rate) in an unconstrained environment suggesting a sudden or very rapid submergence rate (faster than the coral's natural growth rate; Figures 6a and 9). This period was interrupted by a discrete HLS impingement in 1933, followed by a rapid submergence at a slightly lower rate $(5.9 \pm 0.8 \mathrm{~mm}$ /year) than before (Figures $5 \mathrm{a}, 6 \mathrm{a}$, and 9). During almost the same period, between 1934 and 1950, the living coral YOR-1-S1 also recorded a period of submergence at high rate $(5.6 \pm 0.4 \mathrm{~mm} /$ year; Figure $6 \mathrm{c}$ and 9$)$. A striking change in morphology of the Yoron fossil coral YOR-F1 occurred in 1924 with the development of the well-marked external rim in a submergent context at a rapid rate of $5.3 \pm 0.8 \mathrm{~mm} /$ year until 1940 (Figure 5d). It is noteworthy that the signal of living YOR-1-S1 is similar to fossil YOR-F1 but delayed by 10 years. This highlights the uncertainties (few years) in the chronology we have established by combining U-Th ages and growth band counting. The signal recorded by the three corals is very consistent and reveals a major about 15-20 years long lasting submergence event, sudden or gradual between $\approx 1930 \pm 5$ and $\approx 1950$ in south Okinawa and Yoron. The submergence was about $9 \mathrm{~cm}$ in Yoron (for both YOR-1-S1 and YOF-F1) and about $12 \mathrm{~cm}$ in south Okinawa (Figure 9).

After this submergence event, the microatoll ITO 2 recorded a permanent RSL drop of about $7 \mathrm{~cm}$ between 1950 to 1960 with an emergence rate of $5.6 \pm 1.5 \mathrm{~mm} /$ year (Figures 6a and 9). This episode coincides in time and in amplitude with a period of RSL decrease between 1950 and 1968 recorded by YOR-1-S1 through numerous HLS impingements from which we calculated an emergence rate of $2.6 \pm 0.6 \mathrm{~mm} /$ year (Figures $6 \mathrm{c}$ and 9). This episode was also recorded by YOR-11-S1 between 1956 and 1965 and results in several HLS impingements starting in 1956 in a rather stable setting that followed a long period of radial growth in an unconstrained environment (Figures 7c and 8c). Similarly, the ONNA 2 coral also reached its first HLS during this period in 1961 (Figure 9). The fossil coral YOR-F1 in Yoron died around $1965 \pm 2$ during the same period (Figure 5d). Few years before its death, the coral was very thin (17 cm, Figure $5 \mathrm{~d}$ ). Most of the corallites of the corals were likely dead, probably due to an accumulation of sand at the base of the coral, maybe during a tropical storm, and a small emergence event was sufficient to kill this remaining and fragile marginal living part. Overall, our observations suggest that a major RSL drop, of about $7 \mathrm{~cm}$ of amplitude and that occurred between 1950 and 1960-1968, has affected all corals of the region both in Okinawa and Yoron.

Over a shared period, between 1960 and 2016, the records of Itoman and Onna are in good agreement with a stability of the relative sea level in Itoman and a slight emergence at Onna interrupted by die down events, 
which are better preserved in the Itoman record (Figures 9 and Table 3). In Yoron, over the same period, the signal is very different with an alternation of phases with rapid coral upward growth (sudden or gradual submergence) and 6 to 18 years long periods during which the coral was close to its HLS and recorded a signal of emergence (Figures 5c, 6c, 9, and Table 3). From this combination of submergence and emergence periods, we calculated a mean submergence rate of about $0.6 \mathrm{~mm} /$ year over the last 48 years (between about 1968 and 2016 in Figure 9). After the subtraction of the RSL increases recorded by YOR-1-S1 since 1968 (15 cm in total during the two submergence periods), we calculate a net emergence trend of about $2.5 \mathrm{~mm} / \mathrm{year}$ (Table 3 and Figure 9). Similarly, we calculate a mean rate of submergence of $1 \mathrm{~mm} /$ year for YOR-11-S1 between 1965 and 2016 (Figure 7c and 8c). By removing the RSL increases of the two submergence periods having occurred around the same time as YOR-S1 (20 cm in total, Figure $8 \mathrm{c})$, we calculate a net emergence of $3 \mathrm{~mm} /$ year (Figures $8 \mathrm{c}$ and Table 3). These emergence rates of 2.5 and $3 \mathrm{~mm} /$ year are in good agreement with the slight emergence trend inferred from Okinawa records.

\subsection{The Coral Signal Versus Tide Gauge and Satellite Records}

In order to better understand the RSL signal inferred from coral records, we have analyzed the signal from the available tide gauges in the Ryukyu Arc (Figure 1a). We have considered records over the whole arc to decipher the origin of the RSL signal (regional and/or local). We selected the six longest records (ranging from 30 years for the shorter record of Nakanoshima to 55 years for the longest record of Naze, Figure 10b) to minimize, as much as possible, bias in sea-level trend due to interannual and interdecadal sea-level variations (e.g., Douglas \& Peltier, 2002). Two tide gauges are available at Okinawa island (Naha and Okinawa tide gauges; Figures 1 and 10b). Unfortunately, we did not find any record in Yoron island. The RSL rates, calculated by linear regression, range between $0.5 \pm 0.7 \mathrm{~mm} /$ year at Naze and $4.4 \pm 1.5 \mathrm{~mm} /$ year at Nakanoshima (Figure 10b). The RSL rates vary from one island to another one (Figures 1 and 10b). Over a shared period, the two closest tide gauges of Naha and Okinawa recorded a similar submergence rate of $1 \mathrm{~mm} /$ year for the last 40 years (Figure 10b). This slight submergence differs from the stability to slight emergence recorded by the corals of Okinawa (Figures 9 and 10b). When the mean RSL rate is small and the record is short, however, the morphology of microatolls may vary from a subtle cup to a subtle hat shape at the same site. This has been observed among coral microatolls from Haiti, which have grown in a context of very slow-increasing sea level (Weil-Accardo, Feuillet, Jacques, Deschamps, Saurel, et al., 2016). In such cases, the short period RSL fluctuations might have a large impact on corals, as well as on tide gauges, and longer records are needed to estimate the mean rate.

Numerous annual extreme RSL drops were recorded by the tide gauges of Naha and Okinawa like in 1980, 1986, 1995, and 2014 (blue circles in Figure 10b), which were also recorded as die downs by the microatolls of Onna and Itoman. This is an excellent indication of the reliability of the coral microatolls to record such interannual RSL fluctuations as natural tide gauges. In the coral stratigraphy, die downs are followed the year after by upward growth for several years, which implies a temporary origin. As well, we can observe in tide gauges that the sea level goes back to its initial level in the following months to one year in general. These emergence events are likely drived by climatic modes (as the El Nino South Oscillation in the Pacific Ocean, the Indian Ocean Dipole in the Indian Ocean or the North Atlantic Oscillation in the Atlantic Ocean), with an interplay between ocean and atmosphere that generates changes in wind, sea-surface temperature and the sea level (e.g., Becker et al., 2012; Lombard et al., 2005). Interannual sea-level drops of climatic origin have been previously identified in coral microatolls (e.g., Meltzner et al., 2010; Philibosian et al., 2014; Woodroffe \& McLean, 1990; Woodroffe \& Gagan, 2000). Further investigation of the origin of the die downs recorded by Ryukyu microatolls is beyond the scope of this paper, because a study at a more regional scale would be required, as well as geochemical analysis (e.g., $\delta^{18} \mathrm{O}, \mathrm{Sr} / \mathrm{Ca} . .$. ; Abram et al., 2008). Temporary positive sea-level anomalies are also observed in the Ryukyu tide gauges but as for the negative anomalies, the sea level goes back to its initial level rapidly. This is not observed in coral microatolls that rather recorded submergence for several years.

The longest tide gauge of Naze is located $180 \mathrm{~km}$ northeast of Yoron (Figure 1a) recorded between 1961 (beginning of its record) and 1969 four successive RSL drops that create a negative RSL trend with a total amplitude of about $11 \mathrm{~cm}$ (Figure 10b). This coincides with the 10-5 years long period of $7 \mathrm{~cm}$ RSL drop recorded by corals microatolls between 1950 and 1960-968 (Figure 9). As well, a decadal regional sea-level drop is found at the same time in tide gauge records from Japan mainland (Sasaki et al., 2017) that would reflect multidecadal sea-level oscillations driven by climate variability. Indeed, the work of Meyssignac et al. (2012) highlighted that regional sea-level trend patterns are not long-lived features. As an example, they 


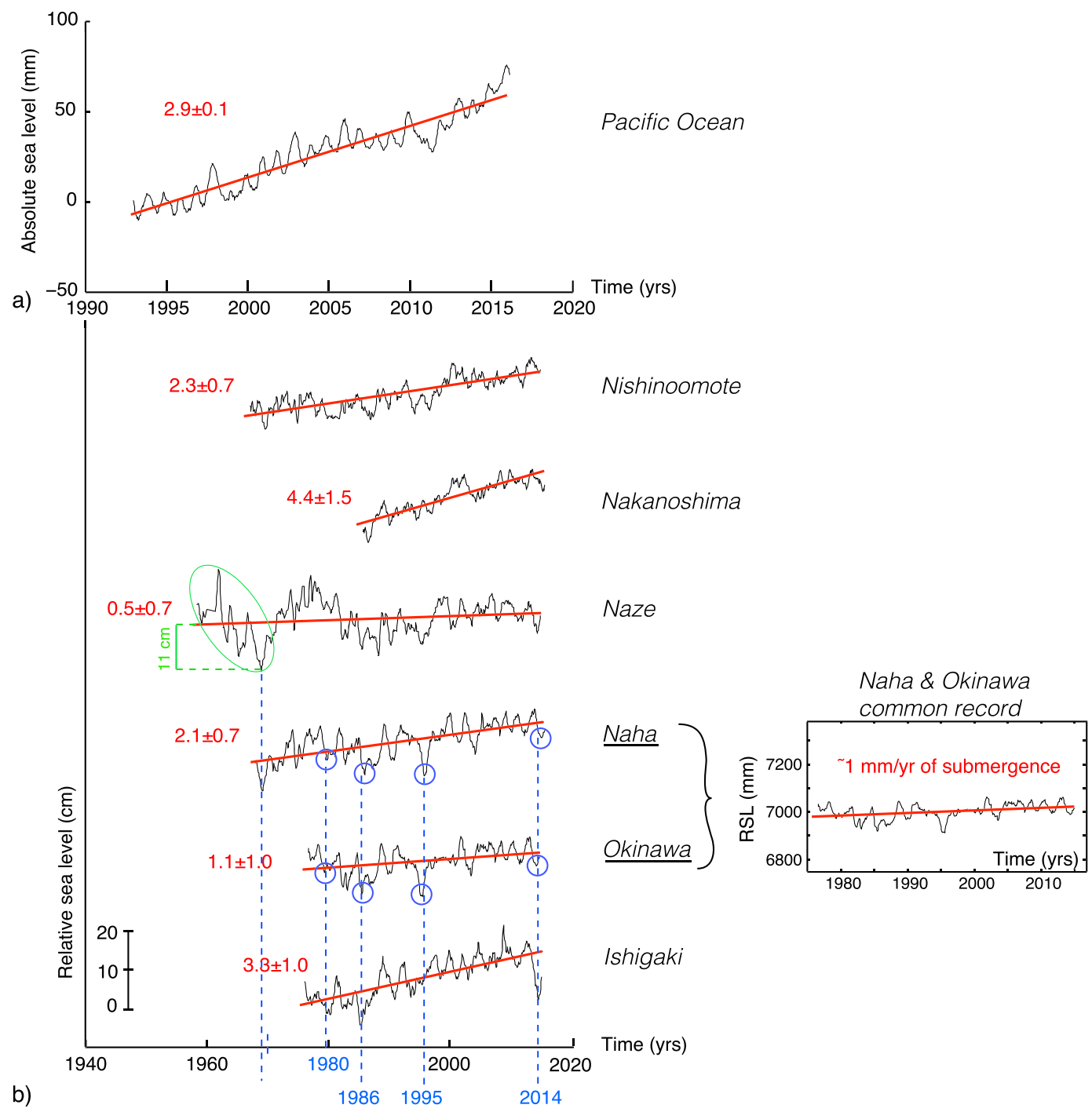

Figure 10. Other regional RSL records. (a) Satellite altimetry data (NOAA data) for the Pacific Ocean. The regionally rising trend of about $3 \mathrm{~mm} /$ year since 1992 would have been almost unchanged since 1950 according to sea-level reconstruction of Meyssignac and Cazenave (2012). (b) Tide gauges (PSMSL annual data) with trend (straight red lines with rate in millimeter per year, with $2 \sigma$ uncertainty). Green ellipsis and dashed green lines: period between 1961 and 1969 during which the Naze tide gauge recorded an emergence trend (see text). Blue circles and dashed blue lines: interannual RSL drops recorded by the tide gauges, in synchronicity with the die downs recorded by microatolls (see text). The two surrounding tide gauges of Naha (1967-2015) and Okinawa (1975-2015) recorded slow submergence (around $1 \mathrm{~mm} /$ year over the shared period 1975-2015).

identified east-west oscillation every 17 years in the tropical Pacific mainly driven by the El Nino South Oscillation (Meyssignac et al., 2012). In their sea-level reconstructions, however, the signal in the Ryukyus appears rather stable through time (Meyssignac et al., 2012). In any case, the permanency of the RSL drop, at least in the Itoman coral record (Figure 9), differs with the temporary sea-level oscillations observed in Naze. This might mean that the synchronicity between coral and the Naze records (and possibly other tide gauges from Japan mainland) for that drop is only a coincidence, and their origins are likely different.

In Naha, we have access to a value of the vertical land motion because the Naha tide gauge is colocated with a GPS. The GPS data are available at the Sonel website (http://www.sonel.org/) and are used to correct the RSL changes recorded by the tide gauges from local or more regional tectonic signals (e.g., Wöppelmann \& Marcos, 2016). Between 2004 and 2014, the Naha GPS recorded $0.53 \pm 0.35 \mathrm{~mm} /$ year of uplift, leading to an absolute sea-level trend of $2.68 \pm 0.49 \mathrm{~mm} / \mathrm{year}$ (http://www.sonel.org/ and Naha tide gauge record in Figure 10). The two closest other tide gauges colocated with nearby continuous GPS—Chichijima in the 
Ogasawara islands and Apra Harbor in Guam island-gave similar absolute sea-level trends with rates of $2.71 \pm 0.95$ and $2.22 \pm 0.89 \mathrm{~mm} /$ year (http://www.sonel.org/).

These values are in good agreement with satellite altimetry that indicates a homogeneous regional sea-level rise in the Ryukyus of $2.9 \pm 0.1 \mathrm{~mm} /$ year since 1992 (Figure 10a). The sea-level reconstructions from Meyssignac and Cazenave (2012) and Meyssignac et al. (2012) indicate a rather steady regional sea-level rise at about $3 \mathrm{~mm} /$ year since 1950 in the study area.

The sea-level pattern of climatic origin is rather homogeneous at the scale of the Ryukyu Arc and would have been unchanged since 1950 according to sea-level reconstructions of Meyssignac and Cazenave (2012) and Meyssignac et al. (2012). The coral signal of Yoron and Okinawa over the last 65 years contrasts with a linear absolute regional sea-level rise of $3 \mathrm{~mm}$ /year. Moreover, the morphology of the microatolls differs from site to site among all of the islands we visited in the central Ryukyu Arc (Figure S1). Similarly, the six tide gauges we selected over the Ryukyu Arc (Figures 1a and 10b) also recorded various RSL trends, that support regional RSL variability along the arc. Overall, both the coral and tide gauge records cannot be fully accounted for by a homogeneous sea-level rise at a regional scale. We need additional signal of tectonic motions (either subsidence or uplift) superimposed to the absolute regional sea-level rise to explain the RSL records.

To estimate the amplitude of such tectonic motions, we have corrected the raw RSL rates over the last 65 years of the coral records for an absolute sea-level rise of $3 \pm 1 \mathrm{~mm} /$ year that might have been unchanged since 1950 (Meyssignac \& Cazenave, 2012). The results are summarized in the last column of Table 3. We thus determined uplift rates that ranges between $2.9 \pm 1.0$ and $8.6 \pm 1.8 \mathrm{~mm} /$ year in Okinawa and between $1.6 \pm 2.1$ and $11.8 \pm 2.2 \mathrm{~mm} /$ year in Yoron.

For the periods of submergence for which the upward growth appears to be unconstrained (all submergence rates written in red in Table 3 with the term MIN added), it is difficult to decipher between a sudden submergence event or a gradual submergence trend. In case of a rather gradual submergence, the lack of contact between the coral upper surface and a HLS surface means that the submergence has to be faster than the raw submergence rate we inferred from the coral, which is thus a minimum value of that submergence. We also subtracted the regional sea-level rise signal from those minimum rates to infer minimum corrected submergence rates (last column of the Table 3).

\section{Possible Sources of the Land-Level Changes 5.1. Crustal Active Faulting}

The land-level changes recorded by our corals and the tide gauges may be related either to local crustal active faulting and/or to the seismic cycle of the Ryukyu megathrust. The Iwo-Tori-shima active volcano, which is the closest from our sampling sites, is too far (about $100 \mathrm{~km}$ northwest of Yoron and more than $150 \mathrm{~km}$ far from Onna and Itoman) to have promoted deformation at our sites.

The central Ryukyu Islands are affected by numerous active faults either related to back-arc spreading in the Okinawa Trough or to arc-parallel extension in the fore-arc domain (Arai et al., 2018, and references therein).

The Okinawa Trough initiated in the Miocene time. It underwent at least two stages of rifting (Kimura, 1985; Lee et al., 1980; Letouzey \& Kimura, 1986; Sibuet et al., 1987, 1998) and is still active today. It is bounded by arc-parallel en echelon active normal faults, which offset the seafloor by several meters (Arai et al., 2018; Sibuet et al., 1987, 1998) and are associated with microseismicity (Sato et al., 1994). The GPS data allow for estimating spreading rate decreasing northward from 50 to $10 \mathrm{~mm} /$ year along the Okinawa Trough (Nishimura et al., 2004) implying that slip rates may range between a few tenths of a millimeter per year and a few millimeters per year along individual faults. Those rates are comparable to vertical slip rates determined for other normal faults in a similar back-arc setting (e.g., Feuillet et al., 2004; Villamor \& Berryman, 2001).

Arai et al. (2018) and Goto et al. (2018) also documented the existence of arc perpendicular normal faults in the arc and the fore-arc domain. Seismic data across the faults show that they cut across Quaternary sedimentary sequences and marine terraces both onshore and offshore. Arai et al. (2018) estimated a slip rate of $0.1 \mathrm{~mm} /$ year along such normal faults. The islands of Yoron and Okinawa are crosscut by active faults belonging to the later system. In Yoron, our sampling sites are located on the footwall of the Tsujimiya fault, $4 \mathrm{~km}$ from its trace (Figure 1b). In Okinawa, the site of Onna is located $5 \mathrm{~km}$ far from a NW-SE active fault 
bounding the Kinbu Bay to the south-west (IAIST, 2016; Figure 1b). Another arc-parallel major normal fault having a several hundred-meter-high scarp and belonging to the back-arc rifting system cuts the seafloor between Yoron and Okinawa and bounds to southeast the Yoron basin (Figure 1b). It moves at a mean rate on the order of $0.1 \mathrm{~mm}$ /year (Arai et al., 2018; Goto et al., 2018). Surface deformations related to motion along those crustal faults are limited within a radius similar to the fault depth (at most tens of kilometers; King et al., 1988). The faults are thus too far or too slow to account for the centimetric scale variations of the relative sea-level we observed in Yoron and Okinawa. We thus retain strain accumulation and release at plate interface as the only possible source of land-level changes to fully explain the RSL changes we documented with coral microatolls.

\subsection{Megathrust Seismic Cycle}

The vertical deformations of the upper plate due to continuous loading on the plate interface during the interseismic period accumulate slowly, at rate on the order of few millimeters per year (Métois et al., 2012; Sieh et al., 2008), whereas the coseismic deformations are sudden (few seconds) and may reach several tens of centimeters to few meters (e.g., Meltzner et al., 2006; Vigny et al., 2011). Transient slip events such as low frequency earthquakes, slow slip events, afterslips, silent earthquakes of different frequencies, magnitudes, duration, and recurrence time depending on when and where they are nucleated along the plate interface (and references therein Ide et al., 2007), have been recently documented both with geodetic and seismological data (Chlieh et al., 2007) and coral microatolls (Meltzner et al., 2015) along several active margins at different stages of their seismic cycle, either during the interseismic period (Kostoglodov et al., 2003), just before (Kato et al., 2012; Ruiz et al., 2014) or just after an earthquake (Nakamura, 2009a; Rolandone et al., 2018).

Several clusters of slow slip events have been documented in the GNSS continuous data at various depths (between 0 and $60 \mathrm{~km}$ ) all along the Ryukyu subduction zone (Nishimura, 2014). In the southern Ryukyus, the SSE events occur at various time intervals, with various magnitudes and durations. Beneath Ishigaki and Iriomote, biannual SSE occur in the transition zone between 20 and $40 \mathrm{~km}$ (Heki \& Kataoka, 2008). The horizontal and vertical deformations promoted at the surface by such events are small, on the order of few millimeters. Elastic models of GNSS data show that they rupture a 70-km-wide and 90-km-long asperity by few centimeters promoting magnitude class 6 slow earthquakes.

In the area of Okinawa and Yoron, several clusters of SSE are also recorded at depth between 5 and $15 \mathrm{~km}$, around $20 \mathrm{~km}$ and between 30 and $40 \mathrm{~km}$ (Nishimura, 2014; Nakamura, 2017). The total slip accommodated by those clusters is about $0.2 \mathrm{~m}$ in the last 17 years (Nishimura, 2014; Nakamura, 2017). This represents a small portion (15\%) of the total convergence along small areas of a few hundreds of square kilometers. In front of Okinawa island, the SSE cluster consists of small magnitude events $(\mathrm{Mw}<6.0)$ that induce very small horizontal deformation (less than $2 \mathrm{~mm}$ ) and vertical deformation of the same order of size (Nishimura, 2014; Nakamura, 2017).

Our coral data allow for documenting sudden or few years long lasting changes in RSL that could be related to SSEs. At the site of Itoman in Okinawa, we have documented a rapid upward growth of $19 \mathrm{~cm}$ starting after 1906 (Figure 9). This RSL increase may have been promoted by a land subsidence, which could have been either sudden or few years long (until 1933, where the next HLS was recorded by ITO 2, Figure 9) or a combination of both. The magnitude of this deformation is on the same order of size than those observed during earthquakes or during the largest SSE (centimetric vertical deformation were recorded with GPS in Mexico and New Zealand, Larson et al., 2007; Wallace \& Beavan, 2006). No large earthquake was reported in front of Okinawa at that time. However, it is noteworthy that this event occurred close in time to the 1911 Kikai earthquake (just before or after by considering few years of uncertainties on growth band counting). After 1933 until 1950, the ITO 2 microatoll kept recording submergence by about $12 \mathrm{~cm}$ gradually at a fast rate of $5.9 \pm 0.8 \mathrm{~mm} /$ year or suddenly, or a combination of both (Figures $6 \mathrm{a}$ and 9 ). This submergence episode was also recorded in Yoron by the two microatolls YOR-F1 and YOR-1-S1 but with a smaller value of about $9 \mathrm{~cm}$ (Figures 5c, 5d, 6c, 6d, and 9). This episode may correspond to a 15-20 years long transient SSE.

In Yoron, two other periods of fast upward growth have occurred between 1968 and 1980 (1965-1981 for YOR-11-S1) and between 1986 and 2000 (1987-2000 for YOR-11-S1; Figure 5c, 6c, 7c, 8c, 9, and Table 3). They might have been triggered by rapid or sudden RSL increases in 1965 (or 1968) and 1986 (or 1987). These submergence episodes recur with a time interval of several tens of years (between 6 and 18 years, including the first event recorded by YOR-1-S1 between 1934 and 1950), with always the same amount of RSL increase 
( $\approx 10 \mathrm{~cm})$. As for the first event (1934-1950 for YOR-1-S1), they might be related to a transient deformation (subsidence) due to slow earthquakes. Such events are one order of size larger and recur with much longer time interval compared to the high frequency SSE documented up to now in the region (Nishimura, 2014; Heki \& Kataoka, 2008). They likely highlight very different slow slip processes.

In between such sudden or transient subsidence events, our corals recorded a more steady emergence (Table 3), which is likely uplift due to strain accumulation along the locked plate interface during the interseismic period. In Yoron, which is located $140 \mathrm{~km}$ far from the trench, the microatolls recorded uplift ranging between $1.6 \pm 2.1$ and $11.8 \pm 2.2 \mathrm{~mm} /$ year (Table 3). In Okinawa, the microatolls recorded uplift ranging between $2.9 \pm 1.0$ and $8.6 \pm 1.8 \mathrm{~mm} /$ year at Itoman and around $4.0 \pm 1.2 \mathrm{~mm}$ at Onna, at distances of 115 and $140 \mathrm{~km}$ from the trench, respectively (Table 3). Those rates vary through time. In Yoron, uplift rates recorded by the microatolls between 1950 and 1987 range between $1.6 \pm 2.1$ and $6.7 \pm 2.2 \mathrm{~mm} /$ year, and stronger uplift were recorded between 2000 and 2016 (Table 3). Also, all corals were affected by 10-15 years of emergence between about 1950 and 1960-1968 (about $7 \mathrm{~cm}$ of total amplitude, as measured on living corals of Itoman and Yoron, Figure 9) that corresponds to a rapid uplift rate in Itoman, which decreased thereafter. The fossil coral YOR-F1 was likely killed by this event in $1965 \pm 2$ (considering uncertainties in the U-Th dating and the growth bands counting). Another similar period of stronger emergence was recorded between 1890 and 1906 by the coral ITO 2 in Okinawa (Figure 9). This event occurred before the sudden and/or rapid 1906-1933 subsidence signal. Those changes in rate might be related to an increase in rate of interseismic strain accumulation. Such transient events during the interseismic period have been observed in corals from Indonesia (Meltzner et al., 2015), mainly before large earthquakes, however.

A small change in submergence rate (between $0.1 \pm 0.1$ and $1.0 \pm 0.1 \mathrm{~mm} /$ year) was also documented by the record of the Yoron fossil microatoll around 1764 (Figure 6d). Within uncertainties on the chronology, this change corresponds to the occurrence of an earthquake in 1768 (Tadokoro et al., 2018). Between 1670 and 1900, the fossil coral YOR-F1 recorded a slow submergence (Figures 6d and Table 3), which, depending on the regional sea-level trend at that time, would imply interseismic subsidence or interseismic uplift, slower than the rate inferred from living corals. Such changes in rate might reflect either variations in interplate coupling rate along a same locked patch or a change in location of the coupled patches (e.g., Meltzner et al., 2015; Weil-Accardo, Feuillet, Jacques, Deschamps, Beauducel, et al., 2016).

\section{Elastic Modeling}

To estimate and discuss both the geometry and magnitude of the transient events and the pattern of strain accumulation along the coupled zone during the interseismic period, we modeled the tectonic deformations recorded by our corals with simple, conventional and widely used elastic dislocation models (Kanda \& Simons, 2010; Kanda et al., 2012; Okada, 1992; Savage, 1983) in 2D in an elastic half space with $\lambda=\mu=32 \mathrm{GPa}$.

To achieve this goal, we need information on the geometry of the plate interface beneath Yoron and Okinawa. We used the SLAB1.0 model (Hayes et al., 2012), which combines all information from seismicity and from geophysical imagery, including the seismic refraction survey near the trench of Kodaira et al. (1996) for proposing a geometry for the slab in the central Ryukyu Arc. Several Multichannel seismic (MCS) profiles were acquired all along the Ryukyu Arc and recently published by Nishizawa et al. (2017). Unfortunately, no MCS data were acquired in between Yoron and Okinawa, but we verified that the depth of the slab along all the MCS profiles is coherent with those estimated by the SLAB1.0 model, making reasonable the use of the later model.

In front of Yoron, the slab dips gently by $13^{\circ}$ between 0 and $20-\mathrm{km}$ depth, then by $20^{\circ}$ between 20 and 30 $\mathrm{km}$ and then plunges with angles ranging between $27^{\circ}$ and $40^{\circ}$ between 30 and $100-\mathrm{km}$ depth (Figure 11a). In Okinawa, the geometry of the plate interface is more complex. The SLAB 1.0 model shows that the mean dip of the slab is $10^{\circ}$ between 0 and $20-\mathrm{km}$ depth, $15^{\circ}$ between 20 and $30 \mathrm{~km}$ and then plunges with angles ranging between $22^{\circ}$ and $40^{\circ}$ between 30 and 100-km depth (Figure 11b). The MCS profile ERC7 located south of Okinawa shows that the Moho is 30-km deep (Nishizawa et al., 2017).

\subsection{Interseismic Deformation}

Several strategies have been developed to model interseismic deformation in a subduction zone (see review by Kanda \& Simons, 2010and references therein). The simplest and widely used model is the back-slip model on planar faults (Savage, 1983). More recently, Kanda and Simons (2012) have developed a more realistic 


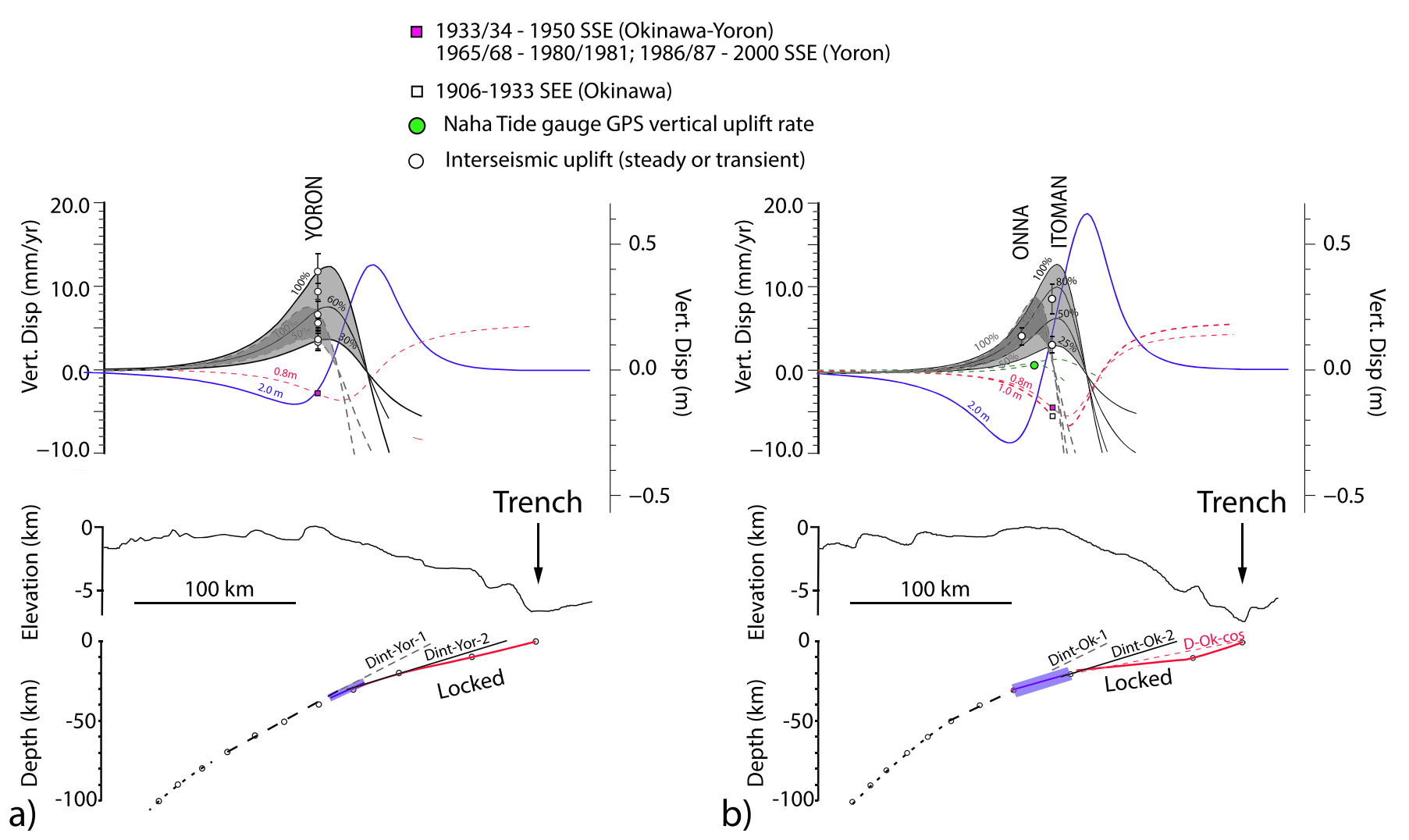

Figure 11. 2D Elastic models of the seismic cycle. All models are performed in an elastic half space with $\lambda=\mu=32$ Gpa. (a) Deformation at the surface induced by motion along different portion of the plate interface in front of Yoron during the seismic cycle. Dashed grey curves and dark grey area: vertical deformation rate (mm/year) promoted by backslip along the dislocation Dint-Yor-1 (dashed grey line on the cross-section of the slab beneath) during the interseismic period. Black curves and light grey areas: vertical deformations rate (mm/year) promoted by backslip along the dislocation Dint-Yor-2 (black line on the cross-section of the slab beneath) during the interseismic period. Values in \% indicate the coupling rate (100\% full coupling, 50\% half coupling). Dashed red curve: vertical deformation at the surface ( $\mathrm{m}$, right scale) promoted by slip of $0.8 \mathrm{~m}$ on the plate interface between 0 and $30-\mathrm{km}$ depth (above the coupling zone, red line on the cross-section of the slab beneath) during an earthquake or a slow slip event. Blue curve: vertical deformation at the surface (m) induced by a slip of $2 \mathrm{~m}$ in the transition zone (blue line on the cross-section of the slab beneath). White dots: values of interseismic deformation rates (mm/year) measured in Yoron at different time period (see Table 3). Pink square: average value of likely sudden subsidence motion $(\mathrm{cm})$ recorded in Yoron in 1934, 1965, or 1968 and 1986 or 1987 (see main text). Slab depth from the SLAB1.0 model (see text), topography from GeomapApp database (http://www.geomapapp.org). (b) As in a but for Okinawa with a different geometry of the slab and different values of interseismic rates (see Table 3). Dashed red curves: vertical deformation at the surface (m) induced by a slip of 0.8 and $1 \mathrm{~m}$ in the shallower part of the plate interface between 0 and $20 \mathrm{~km}$ (D-Ok-cos, dashed line on the cross-section of the slab beneath). White square: value of the likely sudden subsidence recorded in Itoman after 1906 until 1933. Pink square: value of the subsidence recorded in Itoman between 1933 until 1950. Green dots: value of the GPS vertical motion in Naha, Okinawa (http://www.sonel.org/, Wöppelmann \& Marcos, 2016). Dashed green curves: vertical deformation during interseismic period for a coupling rate of $10 \%$ or less (see text). The black dashed curve below 30 -km depth on the cross-section of the slab represents the dipping plate.

elastic subduction plate model with curved geometry. They showed that, at distance beyond two times the depth of the locking depth, the surface deformation can be approximated by locking along a planar fault tangential to that interface near the bottom of the locking fault.

To model the vertical deformation on the surface during the interseismic period in which slip occurs at the deeper part of the plate interface beyond the downdip limit of the coupling zone, we used classical back-slip models on planar dislocation tangential to the interface at the locking depth.

In the Yoron area, the microatolls have recorded uplift ranging between $1.6 \pm 2.1$ and $11.8 \pm 2.2 \mathrm{~mm} /$ year (last column in Table 3), at a distance of about $140 \mathrm{~km}$ from the trench. Given the geometry of the slab in this area, this suggests that strain is accumulating until depth of about $30 \mathrm{~km}$ (until the Moho), considering that the area of maximum uplift rates corresponds to the downdip limit of the locking zone (Kanda \& Simons, 2012). This depth corresponds also to a strong increase in the slope of the slab. We modeled the expected deformation in $2 \mathrm{D}$ by considering variable coupling rate (full coupling corresponds to $8 \mathrm{~cm} / \mathrm{year}$ of slip deficit) along two different planar dislocations, which are both tangential to the interface near the bottom 
of the locking fault at $30 \mathrm{~km}$ : a $65-\mathrm{km}$-wide dislocation dipping $27^{\circ}$ westward (Dint-Yor-1, dashed grey line and curves on Figure 11a) and a 115-km-wide dislocation dipping $17^{\circ}$ westwards (Dint-Yor-2, black line and curves on Figure 11a).

In Okinawa, the microatolls have recorded uplift ranging between $2.9 \pm 1.0$ and $8.6 \pm 1.8 \mathrm{~mm}$ /year (at Itoman) and around $4.0 \pm 1.2 \mathrm{~mm}$ (at Onna; last column in Table 3) and are at distance of 115 and $140 \mathrm{~km}$ far from the trench, respectively. Given the geometry of the interface in front of Okinawa, this suggests coupling until a depth of $20 \mathrm{~km}$. As in front of Yoron, this depth coincides also to a change in the slope of the slab. We modeled the interseismic deformation expected for strain accumulation along a 40-km-wide dislocation dipping westward by $27^{\circ}$ (Dint-Ok-1, dashed gray line and curves on Figure 11b) and a 75-km-wide dislocation dipping $17^{\circ}$ toward the west (Dint-Ok-2, black line and curves on Figure 11b).

In Yoron, the models predict maximum interseismic deformation rates of $12.5 \mathrm{~mm} / \mathrm{year}$ of uplift (Figure 11a). This is compatible with the value of uplift recorded by the microatoll YOR-11-S1 in the last two decades ( $11.8 \pm 2.2$ between 2000 and 2016, Table 3$)$. High values $(9.4 \pm 1.4 \mathrm{~mm} /$ year) are also recorded by the coral YOR-1-S1 at the same period (Table 3). Smaller uplift rates ranging between $3.2 \pm 1.0$ and $6.7 \pm 2.2 \mathrm{~mm} /$ year were recorded by the microatolls between 1940 and 1987 (Table 3). Those values can be modeled by strain accumulation along a plate interface whose coupling rate varies between $50 \%$ and $100 \%$ on a steeper $27^{\circ}$ dipping interface and with a coupling rate ranging between $30 \%$ and $60 \%$ on a $17^{\circ}$ dipping interface (Figure 11a). We did not take into account the lower uplift rate of $1.6 \pm 2.1 \mathrm{~mm} /$ year recorded between 1956 and 1965 by YOR-11-S1 because the deformation rate $(5.6 \pm 1.2 \mathrm{~mm} /$ year $)$ is better constrained over a longer period (1950-1968) by the neighboring coral YOR-1-S1 at the same period (Table 3).

In Okinawa, the values of uplift measured by the microatolls are ranging between $2.9 \pm 1.0 \mathrm{~mm} / \mathrm{year}$ and $8.6 \pm 1.8 \mathrm{~mm} /$ year in Itoman and are around $4.0 \pm 1.2 \mathrm{~mm}$ in Onna (Table 3). These values can be modeled by strain accumulation along a plate interface with a coupling value ranging between $50 \%$ and $100 \%$ and between $25 \%$ and $80 \%$ with a dip of $27^{\circ}$ and $17^{\circ}$, respectively (Figure $11 \mathrm{~b}$ ).

In between the two sites (Onna and Itoman) in Okinawa, the Naha tide gauge colocated with a GPS recorded an absolute vertical uplift of $0.53 \pm 0.35 \mathrm{~mm} /$ year over 10 years between 2004 and 2014 (Wöppelmann \& Marcos, 2016). This rate is much lower than those recorded by the studied microatolls over longer periods (between 33 and 66 years, Table 3) and would be modeled by strain accumulation along a weakly coupled interface ( $10 \%$ or less, green dashed lines in Figure $11 \mathrm{~b}$ ). This is compatible with the value of coupling estimated by modeling of GPS data (less than $10 \%$ of coupling in front of Yoron and Okinawa, Watanabe \& Tabei, 2004) but contradicts recent geodetic study performed closer to the trench (high coupling on a 50-km-wide patch southeast of Okinawa, Nakamura, 2011; Tadokoro et al., 2018).

Despite the discrepancy of results inferred from GPS studies (Nakamura, 2011; Tadokoro et al., 2018; Watanabe \& Tabei, 2004), which points out the need to increase data set spatially and temporally, this demonstrates that interseismic strain rate is likely not linear and may vary over time scales of few decades or more as observed in other subduction zones where microatolls were studied (e.g., Meltzner et al., 2015; Weil-Accardo, Feuillet, Jacques, Deschamps, Beauducel, et al., 2016). Such variations in interseismic strain rate were also clearly observed in Yoron and Okinawa microatolls.

\subsection{Slip Events}

We modeled in 2D the vertical deformations at the surface that would be promoted by transient SSEs in Yoron by using: (1) the slip of a planar dislocation at shallow depth above the coupling zone dipping by $13^{\circ}$ between 0 and $20 \mathrm{~km}$ and by $20^{\circ}$ between 20 and $30 \mathrm{~km}$ (red dashed curve and red line, Figure 11a) and (2) the slip of a $24^{\circ}$ west dipping planar dislocation in a zone, which could correspond to a transition zone between the sliding deep zone and the locked shallower zone, at depth ranging between 27 and $37 \mathrm{~km}$ (blue curve and line, Figure 11a).

In Okinawa, we have modeled the upper plate vertical deformation expected for (1) an SSE along a shallow dislocation dipping $11^{\circ}$ to the west and extending between the trench $(0 \mathrm{~km})$ and $20 \mathrm{~km}(\mathrm{D}-\mathrm{Ok}-\mathrm{cos}$, dashed red line and curves, Figure 11b) and (2) an SSE in the transition zone along a dislocation dipping westward by $16^{\circ}$ extending between 20 - and $30-\mathrm{km}$ depth (blue line and curve on Figure 11b). In Figure 12, we have drawn the possible pattern of the SSEs.

Around 1933-1934, the corals ITO2, YOR-1-S1, and YOR-F1 (around 1924) in Itoman and Yoron recorded a 15-20 years long lasting slow subsidence at rate of several millimeters per year with an amplitude of $12 \mathrm{~cm}$ 
1906-1933

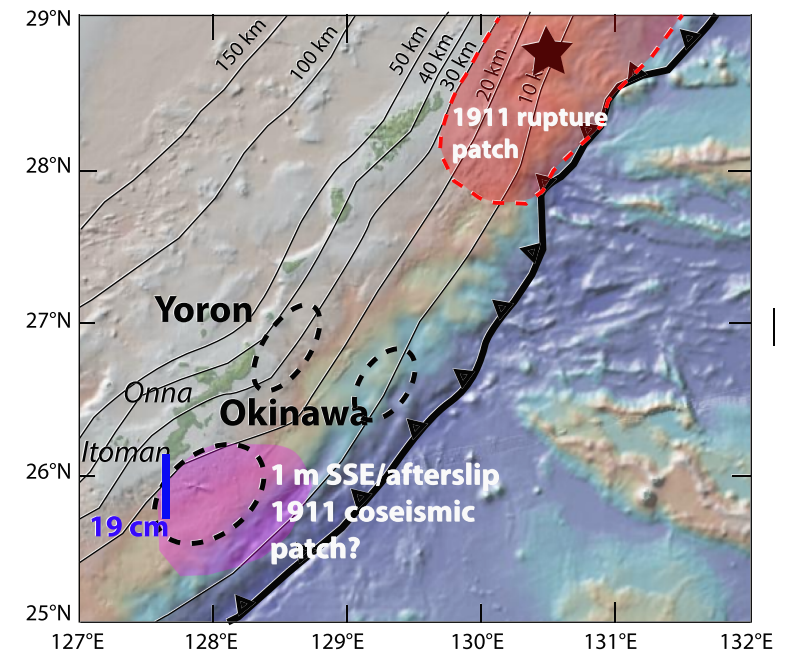

a) $1965(68)-1980(81)$ $1986(87)-2000$

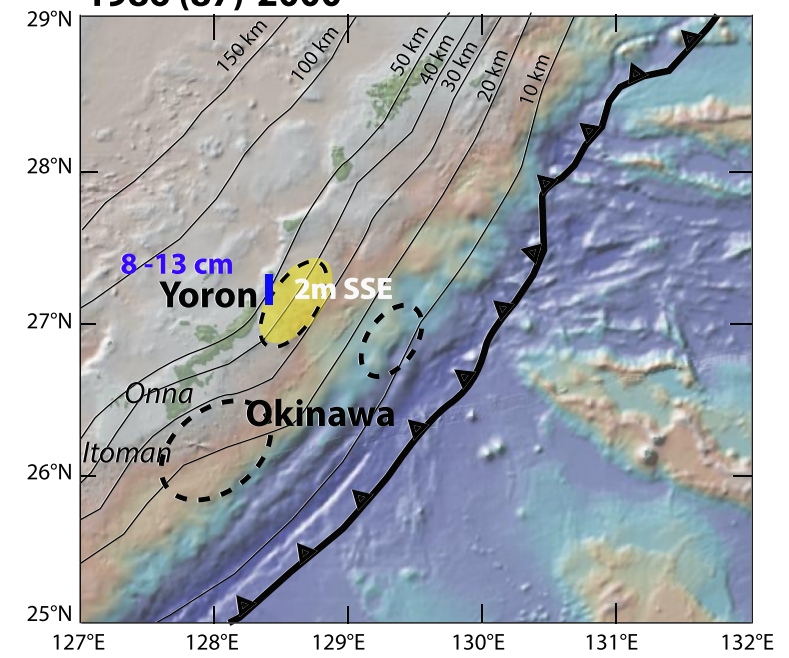

c)

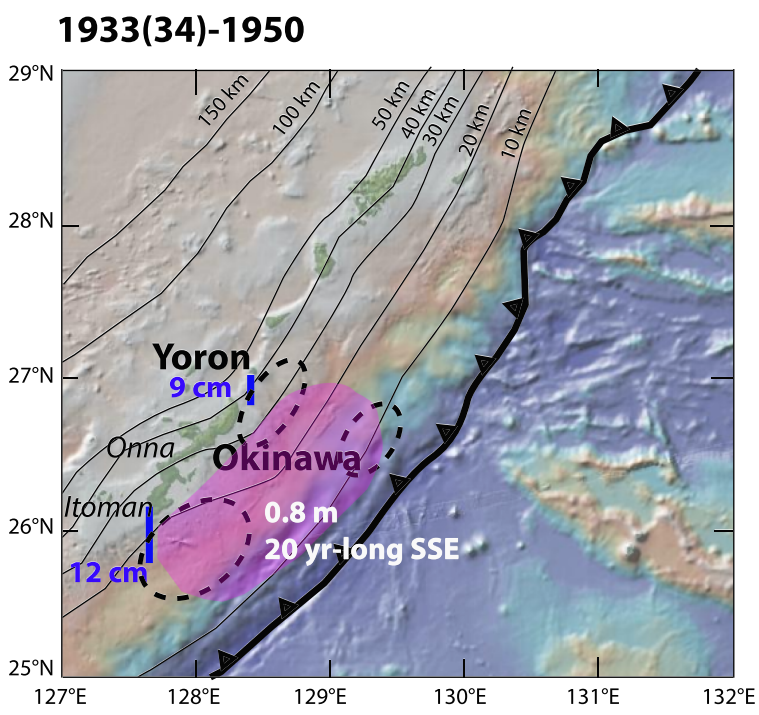

b) $1965(68)-1980(81)$ $1986(87)-2000$

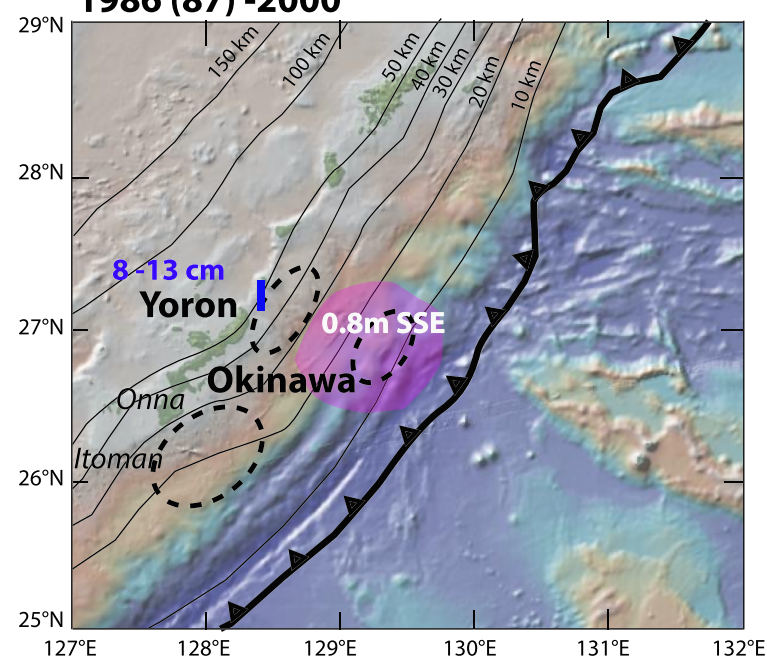

d)

Figure 12. Possible pattern of slip events responsible for the submergence events recorded by the microatolls. Dashed black ellipses: regions of SSE from (Nishimura, 2014; Nakamura, 2017). Red ellipse: possible ruptured area of the June 151911 M8 Kikai earthquake. Star: 1911 earthquake epicenter from Goto et al. (2013). Purple ellipses: possible SSE areas in the upper part of the megathrust (coupling zone). Yellow ellipses: Possible SSE area in the transition zone in Okinawa.

in Okinawa and $9 \mathrm{~cm}$ in Yoron. This can be very well modeled by a slow slip of $0.8 \mathrm{~m}$ along the coupling zone at shallow depth (Figures 11 and 12b). This event extending between Yoron and the southern coast of Okinawa may have been $\approx 200 \mathrm{~km}$ long and $\approx 100 \mathrm{~km}$ wide (Figure $12 \mathrm{~b}$ ), corresponding to a Magnitude 7.7 event (with $\mu=32 \mathrm{GPa}$ ). This SSE may have occurred within zones where other SSEs have been documented with seismologic and geodetic data (dashed black ellipses on Figure 12; Nishimura, 2014; Nakamura, 2017).

The two other subsidence episodes with values of about 8-13 cm observed in Yoron between 1968 and 1980 (1965-1981 for YOR-11-S1) and between 1986 and 2000 (1987-2000 for YOR 11-S1; Figures 5c, 6c, 7c, 8c, 9, and Table 3) can be modeled either by a slip of $0.8 \mathrm{~m}$ at shallow depth $(0-30 \mathrm{~km}$, red dashed curve on Figure 11a) or by a larger slip of $2 \mathrm{~m}$ in the transition zone (blue curve on Figure $11 \mathrm{a}$ ). The two hypotheses are represented in Figures 12c and 12d. The possible pattern of the SSEs we documented is again compatible with the location of areas where other numerous SSEs have been documented with seismologic and geodetic data (Figures 12c and Fig12d). The sliding areas are about 50 and $100 \mathrm{~km}^{2}$, implying a magnitude of 7.5 for a slip of 2 and $0.8 \mathrm{~m}$, respectively. Such a slow slip occurring every 13 years (average value of the recurrence 
time between subsidence episodes) may account for a significant part of the convergence along the transition zone or along the upper portion of the megathrust. In the latter case, the SSEs may contribute to release more than two thirds ( $0.8 \mathrm{~m}$ each 13 years) of the strain accumulated on those patches and to significantly delay the occurrence of an earthquake in these areas.

In Okinawa, a slip of $1 \mathrm{~m}$ on the shallower portion of the plate interface can promote subsidence at Onna and Itoman, with a larger amplitude value of $20 \mathrm{~cm}$ expected at Itoman (white square and dashed red curve on Figure 11b). This value is compatible with the submergence of about $19 \mathrm{~cm}$ recorded after 1906 until 1933 by the microatoll ITO 2. This subsidence which is coeval to the occurrence of the 1911 Kikai earthquake, could be due either to a coseismic slip on a patch located in front of Okinawa during the earthquake, a SSE having occurred before the earthquake, or an aseismic postseismic afterslip.

Itoman is located $300 \mathrm{~km}$ southwards from the southernmost epicentral location proposed in the literature for the 1911 Kikai earthquake (Tsuji, 1997; Usami, 1996). We do not observe, significant deformation during this period in the microatolls record from Yoron. However, as Yoron is located as far as Onna from the trench, our simple 2D models predict less than 5 to $10 \mathrm{~cm}$ of subsidence at such a distance from the trench (Figure 11). Moreover, we know from many others and well-known subduction earthquakes that during SSE or classic high-frequency earthquake, the slip is not uniformly distributed and may concentrate in small asperities, some being located far from the epicenter (Chlieh et al., 2008; Nocquet et al., 2017; Sun et al., 2014; Vigny et al., 2011). During the 1911 earthquakes, patches may have ruptured close to the epicenter with a large slip ( $5 \mathrm{~m}$ or more) in front of Kikai promoting a tsunami with a 5-m-high waves, and other patches may have ruptured in front of Okinawa but with much smaller values of slip $(1 \mathrm{~m})$. In front of Yoron, the slip may have been so small that the vertical deformations were too small to have been recorded (or preserved) by microatolls in Yoron. We calculated however, that a slip of $1 \mathrm{~m}$ along a $100-\mathrm{km}^{2}$ rupture in front of Okinawa would have produce a tsunami with 0.5 to 1-m-high waves in most of the main bays of the eastern coast of Okinawa (supporting information, Figure S6). This would have certainly been reported in historical chronicles. More investigations on historical data would be required to firmly conclude, but this is beyond the scope of this paper. The $19 \mathrm{~cm}$ of sudden or very rapid subsidence may have also been triggered by an SSE of $1 \mathrm{~m}$ in the shallow part of the megathrust in front of Okinawa before the occurrence of the earthquake. Patches of up to 1.5-m slow-slip have been documented 150-km far from the rupture in Chile during the 20 days preceding the 2014 M8.1 Iquique Earthquake (Ruiz et al., 2014). Such SSEs may be large enough to cause a stress load sufficient to favor the mainshock rupture (Kato et al., 2012). This subsidence may also have been promoted by an afterslip event following the 1911 earthquake. This was observed after the 2016 M7.8 Pedernales earthquake in Chile, where rapid afterslip occurred in the following 30 days, along patches located up to $150 \mathrm{~km}$ far from the rupture (Rolandone et al., 2018). This sliding event coincides with the area of frequent SSE documented southeast of Okinawa (Figure 12a).

We also calculated that a slip of $2 \mathrm{~m}$ in the transient zone (blue line on Figure 11b) at depth ranging between 20 and $30 \mathrm{~km}$ (along a $16^{\circ}$ westward dipping plane) would promote a subsidence of $25 \mathrm{~cm}$ in Onna and an uplift of $10 \mathrm{~cm}$ in Itoman. Our modeling shows that the emergence events, which occurred between 1950 and 1960 in Okinawa (Itoman) and in Yoron and between 1890 and 1906 in Okinawa (Itoman) could have been promoted by a transient slip event in the deeper portion of the subduction zone (in the transient zone, for Itoman, which is closer to the trench, Figure 11b, or even deeper-not modeled-for Yoron and Onna, which are located farther from the trench). Such an event may correspond to an acceleration of the interseismic strain accumulation. This has been documented in Sumatra or Vanuatu, where the interseismic strain accumulation is not linear and can vary over time scales of few decades (Meltzner et al., 2015; Taylor et al., personal communication, 2014).

\section{Conclusion}

With this first detailed stratigraphic analysis on coral microatoll slabs in the central Ryukyu Arc, we reconstructed the RSL changes over the past centuries with living coral microatolls from Yoron and Okinawa and one large fossil microatoll in Yoron. We highlighted that all corals recorded emergence and that those emergence rates vary through time. We also identified periods of unimpeded upward growth due to sudden and/or gradual submergence.

The comparison of the coral signal to available regional tide gauge records and to satellite altimetry highlighted RSL variability along the arc in contrast to the homogeneous regional sea-level trend. It also 
allowed us to correct the RSL rates inferred from corals for an absolute regional sea-level rise estimated to $3 \pm 1 \mathrm{~mm}$ /year and likely unchanged since 1950. The comparison with the tide gauges also interestingly highlighted the synchronous record of a few interannual RSL drops in both corals (as die downs) and instrumental records, which are likely regional and drived by climate natural variability.

Since the regional sea level can not fully explain the coral signal (variability of the signal in space and time), we suggested that a significant part of the signal is due to tectonics. In the state of our knowledge of the active structures in the central Ryukyu Arc, the megathrust seismic cycle would be the source of such vertical deformations recorded by the microatolls. The emergence trend would reflect uplift due to interseismic loading on the plate interface while submergence events might be due to subsidence promoted by SSEs on the megathrust interface or in the transition zone. According to the slab geometry, Itoman (east of Okinawa) is well located to record the deformations related to the megathrust seismic cycle (located in an area of maximum coseismic subsidence and maximum interseismic uplift) while Yoron and Onna (west of Okinawa), slightly westward from the trench, are good locations for tracking the deep transient events as they are above the transition zone.

By using elastic dislocation forward modeling, we showed that the uplift rates inferred from Okinawa and Yoron corals could be explained by interseismic strain loading on the plate interface with a coupling rate of at least 25\% for Okinawa and 30\% for Yoron. The 25\% of coupling in Okinawa is higher than the $10 \%$ of coupling needed to explain the low uplift rate inferred from the Naha GPS station colocated with a tide gauge (Wöppelmann \& Marcos, 2016). Also, our coupling estimates are higher than the previous coupling estimates along the arc based on GPS data (e.g., Watanabe \& Tabei, 2004) and in better agreement with the work of (Nakamura, 2011; Tadokoro et al., 2018) that evidenced a patch of strong coupling southeast of Okinawa. This range of coupling (that likely changed through time to explain the changes in uplift rate inferred from coral records) highlights the need to get more data to cover a longer timescale than the one given by geodesy to allow discussion on stability of coupling through time and a better assessment of seismic hazard.

We have shown with elastic dislocation forward modeling that the likely sudden 8-13 $\mathrm{cm}$ submergence events recorded by Yoron and Itoman corals (with an averaged frequency of about 13 years in Yoron) could be explained by slip on a deeper part of the megathrust in the transition zone (for Yoron) or by slip on shallow segment of the plate interface (for Yoron and Itoman). These SSEs occurred in an area where frequent SSEs have been reported, but are different from the ones currently recorded along the Ryukyu Arc (smaller and higher frequency), which could suggest a change of the seismic behavior of the megathrust. As an example, coupling change was observed in Indonesia with a stronger coupling few decades before a major earthquake (e.g., Meltzner et al., 2015). Also, the likely sudden subsidence event recorded around 1906 by the longest record of Itoman might be explained by a slip of $1 \mathrm{~m}$ on the shallower part of the interface. The coincidence with the 1911 Kikai earthquake allows several hypotheses for the origin of this slip: coseismic slip on a patch located in front of Okinawa during the earthquake, an SSE having occurred before the earthquake, or an aseismic postseismic afterslip. Corals of Onna and Yoron further west from the trench could have missed the earthquake as the modeled deformations are very small in these two places. It will be important to find additional corals that would have recorded the event to validate this unique observation.

Since the last major likely subduction earthquake in 1911, $8 \mathrm{~m}$ of slip deficit have been accumulated. Only $15 \%$ of the slip deficit might be accommodated by the SSE clusters in the area according to Nishimura (2014) and Nakamura (2017), meaning that a large part might still have to be released (around $7 \mathrm{~m}$ ). This corresponds to an earthquake magnitude ranging between 7 and more than 8 , for $25 \%$ and $100 \%$ of coupling rate, respectively. We have, however, highlighted that SSEs could explain the series of submergence events recorded by corals every 13 years in average and thus might have released more than two thirds of the accumulated strains. This could delay the occurrence of a large damaging earthquake. Nonetheless, the occurrence of SSEs might also load strains on more strongly coupled patches and act as trigger of a larger rupture.

At a larger scale, the regional RSL variability highlighted with microatolls morphology and tide gauges, the distribution of silent earthquakes (e.g., Nakamura \& Sunagawa, 2015) and of paleotsunamis (Goto et al., 2013) along the arc, underlines the segmentation of the arc, which is a crucial information to characterize seismic hazard. Long-term seismic barriers that create a segmentation of the arc, more or less stable through time, have to be identified. In front of the area investigated, such barriers could exist due to the entrance in subduction of the submarine Daito ridge and/or the Luzon-Okinawa Fracture Zone (Figure 1a). 
Despite the need to a better characterization of other active structures at local and regional scale, this first study based on the detailed RSL changes recorded by coral microatolls brought evidences of a complex RSL signal mixing a regional sea-level trend of climatic origin and land-level changes that we assumed to be related to the megathrust seismic behavior. We proposed first assumptions of how the megathrust could explain the RSL changes deduced from corals. Our data indicate an interseismic coupling stronger than most of previous estimates and strengthen the probability of a large tsunami earthquake in the central Ryukyu Arc as already suggested by Nakamura (2011). This first study on the reconstruction of RSL changes using coral microatolls in the Ryukyu islands need to be extended along the arc and also in time by continuing to search for fossil microatolls and for other markers such as reef plateaus and marine terraces. The ubiquity of coral microatolls from north Okinoerabu to south of Okinawa offers promise that we should find good sites along the arc that remains unexplored. This will further enable us to work along transects perpendicular and parallel to the trench, which is highly needed to an accurate understanding of the megathrust behavior (e.g., size of the seismogenic segment, segmentation of the arc) and to confront our first assumptions.

Acknowledgments

This work would not have been possible without the support of many people who helped us for sampling and processing. Town offices and fisherman unions at Yoron town, Onna village and Itoman city provided us logistic help and information on channel opening. Milano Industry Co. Ltd. (Ogyu Manufacturing Inc.) kindly sliced the coral samples. Prof. Manabu Mochizuki from the Department of Veterinary Medical Sciences, the University of Tokyo, offered help for $\mathrm{X}$-raying the coral slices. Field work were supported by the Director's Discretionary Fund of Earthquake Research Institute, the University of Tokyo, and JSPS KAKENHI Grant JP16H01838. Analysis of the relative amount of Aragonite and Calcite elements of the subsamples dated with geochronology was conducted at Advanced Characterization Nanotechnology Platform of the University of Tokyo, supported by "Nanotechnology Platform" of the Ministry of Education, Culture, Sports, Science and Technology (MEXT), Japan. U-Th dating was supported by grants to C-C. Shen from Taiwan ROC Ministry of Science and Technology (105-2119-M-002-001), National Taiwan University (105R7625), and the Higher Education Sprout Project of the Ministry of Education (108L901001). This work was supported by the Labex UnivEarthS, the Institut National des Sciences de l'Univers, Centre National de la Recherche Scientifique (INSU CT3 ALEAS) and the Institut de Physique du Globe de Paris (BQR). Data are included in the main text and supporting information files as figures. Any additional information (coral pictures, xrays, total station data, HLS curves) can be found here: https:// figshare.com/s/c80eca8e485e613438f3.

\section{References}

Abram, N. J., Gagan, M. K., Cole, J. E., Hantoro, W. S., \& Mudelsee, M. (2008). Recent intensification of tropical climate variability in the Indian Ocean. Nature Geoscience, 1(12), 849.

Ando, M., Kitamura, A., Tu, Y., Ohashi, Y., Imai, T., Nakamura, M., \& Shishikura, M. (2018). Source of high tsunamis along the southernmost Ryukyu trench inferred from tsunami stratigraphy. Tectonophysics, 722, 265-276.

Ando, M., Nakamura, M., Matsumoto, T., Furukawa, M., Tadokoro, K., \& Furumoto, M. (2009). Is the Ryukyu subduction zone in Japan coupled or decoupled? The necessity of seafloor crustal deformation observation. Earth, Planets and Space, 61(9), 1031-1039.

Aoki, Y., \& Scholz, C. H. (2003). Interseismic deformation at the Nankai subduction zone and the Median Tectonic Line, southwest Japan. Journal of Geophysical Research, 108(B10), 2470. https://doi.org/10.1029/2003JB002441

Arai, K., Inoue, T., \& Sato, T. (2018). High-density surveys conducted to reveal active deformations of the upper forearc slope along the Ryukyu Trench, western Pacific, Japan. Progress in Earth and Planetary Science, 5(1), 45.

Araoka, D., Yokoyama, Y., Suzuki, A., Goto, K., Miyagi, K., Miyazawa, K., \& Kawahata, H. (2013). Tsunami recurrence revealed by Porites coral boulders in the southern Ryukyu Islands, Japan. Geology, 41(8), 919-922.

Becker, M., Meyssignac, B., Letetrel, C., Llovel, W., Cazenave, A., \& Delcroix, T. (2012). Sea level variations at tropical Pacific islands since 1950. Global and Planetary Change, 80, 85-98.

Briggs, R. W., Sieh, K., Meltzner, A. J., Natawidjaja, D., Galetzka, J., Suwargadi, B., et al. (2006). Deformation and slip along the Sunda megathrust in the great 2005 Nias-Simeulue earthquake. Science, 311(5769), 1897-1901.

Cheng, H., Edwards, R. L., Hoff, J., Gallup, C., Richards, D., \& Asmerom, Y. (2000). The half-lives of uranium-234 and thorium-230. Chemical Geology, 169(1-2), 17-33.

Cheng, H., Edwards, R. L., Shen, C. C., Polyak, V. J., Asmerom, Y., Woodhead, J., et al. (2013). Improvements in 230Th dating, 230Th and 234U half-life values, and U-Th isotopic measurements by multi-collector inductively coupled plasma mass spectrometry. Earth and Planetary Science Letters, 371, 82-91.

Chlieh, M., Avouac, J. P., Hjorleifsdottir, V., Song, T. R. A., Ji, C., Sieh, K., et al. (2007). Coseismic slip and afterslip of the great M w 9.15 Sumatra-Andaman earthquake of 2004. Bulletin of the Seismological Society of America, 97(1A), S152-S173.

Chlieh, M., Avouac, J. P., Sieh, K., Natawidjaja, D. H., \& Galetzka, J. (2008). Heterogeneous coupling of the Sumatran megathrust constrained by geodetic and paleogeodetic measurements. Journal of Geophysical Research, 113, B05305. https://doi.org/10.1029/ 2007JB004981

Denis, V., Mezaki, T., Tanaka, K., Kuo, C. Y., De Palmas, S., Keshavmurthy, S., \& Chen, C. A. (2013). Coverage, diversity, and functionality of a high-latitude coral community (Tatsukushi, Shikoku Island, Japan). PLoS One, 8(1), e54330.

Doo, W. B., Lo, C. L., Wu, W. N., Lin, J. Y., Hsu, S. K., Huang, Y. S., \& Wang, H. F. (2018). Strength of plate coupling in the southern Ryukyu subduction zone. Tectonophysics, 723, 223-228.

Douglas, B. C., \& Peltier, W. R. (2002). The puzzle of global sea-level rise. Physics Today, 55(3), 35-41.

Feuillet, N., Tapponnier, P., Manighetti, I., Villemant, B., \& King, G. (2004). Differential uplift and tilt of Pleistocene reef platforms and Quaternary slip rate on the Morne-Piton normal fault (Guadeloupe, French West Indies). Journal of Geophysical Research, 109, B02404. https://doi.org/10.1029/2003JB002496

Fujita, K., Hongo, C., Koutoku, M., Ito, S., Asami, R., \& Reimer, J. D. (2015). Buried fossil microatolls off the Kaichu-Doro Causeway, between Okinawa and Henza Islands. Fauna Ryukyuana, 24, 13-15.

Goto, K. (2013). Re-evaluation of hypocenter of the 1911 great earthquake around Kikai-jima, Japan. Journal of the Seismological Society of Japan, 2(65), 231-242.

Goto, H., Arai, K., \& Sato, T. (2018). Topographic anaglyphs from detailed digital elevation models covering inland and seafloor for the tectonic geomorphology Studies in and around Yoron Island, Ryukyu Arc, Japan. Geosciences, 8(10), 363.

Goto, K., Kawana, T., \& Imamura, F. (2010). Historical and geological evidence of boulders deposited by tsunamis, southern Ryukyu Islands, Japan. Earth-Science Reviews, 102(1), 77-99.

Goto, K., Miyagi, K., \& Imamura, F. (2013). Localized tsunamigenic earthquakes inferred from preferential distribution of coastal boulders on the Ryukyu Islands, Japan. Geology, 41(11), 1139-1142.

Goto, K., Miyagi, K., Kawamata, H., \& Imamura, F. (2010). Discrimination of boulders deposited by tsunamis and storm waves at Ishigaki Island, Japan. Marine Geology, 269(1), 34-45.

Goto, K., Shinozaki, T., Minoura, K., Okada, K., Sugawara, D., \& Imamura, F. (2010). Distribution of boulders at Miyara Bay of Ishigaki Island, Japan: A flow characteristic indicator of tsunami and storm waves. Island arc, 19(3), 412-426.

Hayes, G. P., Wald, D. J., \& Johnson, R. L. (2012). Slab1. 0: A three-dimensional model of global subduction zone geometries. Journal of Geophysical Research, 117, B01302. https://doi.org/10.1029/2011JB008524 
Heki, K., \& Kataoka, T. (2008). On the biannually repeating slow-slip events at the Ryukyu Trench, southwestern Japan. Journal of Geophysical Research, 113, B11402. https://doi.org/10.1029/2008JB005739

Hiess, J., Condon, D. J., McLean, N., \& Noble, S. R. (2012). 238U/235U systematics in terrestrial uranium-bearing minerals. Science, 335(6076), 1610-1614.

Hopley, D. (1982). The geomorphology of the Great Barrier Reef: Quaternary development of coral reefs. New York, NY: John Wiley \& Sons. Hopley, D. (2011). Encyclopedia of Modern Coral Reefs: structure, form and process. Dordrecht, The Netherlands: Springer Verlag.

IAIST (2016). Active Fault Database of Japan, October 42016 version. Research Information Database DB095 National Institute of Advanced Industrial Science and Technology.

Ide, S., Beroza, G. C., Shelly, D. R., \& Uchide, T. (2007). A scaling law for slow earthquakes. Nature, 447(7140), 76.

Jaffey, A., Flynn, K., Glendenin, L., Bentley, W. t., \& Essling, A. (1971). Precision measurement of half-lives and specific activities of U 235 and U 238. Physical Review C, 4(5), 1889 .

Kan, H. (2011). Ryukyu Islands. In Encyclopedia of modern coral reefs (pp. 940-945): Springer.

Kanda, R. V., Hetland, E. A., \& Simons, M. (2012). An asperity model for fault creep and interseismic deformation in northeastern Japan. Geophysical journal international, 192(1), 38-57.

Kanda, R. V., \& Simons, M. (2010). An elastic plate model for interseismic deformation in subduction zones. Journal of Geophysical Research, 115, B03405. https://doi.org/10.1029/2009JB006611

Kanda, R. V., \& Simons, M. (2012). Practical implications of the geometrical sensitivity of elastic dislocation models for field geologic surveys. Tectonophysics, 560, 94-104.

Kato, A., Obara, K., Igarashi, T., Tsuruoka, H., Nakagawa, S., \& Hirata, N. (2012). Propagation of slow slip leading up to the 2011 Mw 9.0 Tohoku-Oki earthquake. Science, 335(6069), 705-708.

Kawana, T., \& Pirazzoli, P. A. (1985). Holocene coastline changes and seismic uplift in Okinawa Island, the Ryukyus, Japan. Zeichsrift fur Geomorphology, 57, 11-31.

Kimura, M. (1985). Back-arc rifting in the Okinawa Trough. Marine and Petroleum Geology, 2(3), 222-240.

King, G. C., Stein, R. S., \& Rundle, J. B. (1988). The growth of geological structures by repeated earthquakes 1. Conceptual framework. Journal of Geophysical Research, 93(B11), 13,307-13,318.

Koba, M., Nakata, T., \& Takahashi, T. (1982). Late Holocene eustatic sea-level changes deduced from geomorphological features and their 14C dates in the Ryukyu Islands, Japan. Palaeogeography, Palaeoclimatology, Palaeoecology, 39(3-4), 231,239-235,260.

Kodaira, S., Iwasaki, T., Urabe, T., Kanazawa, T., Egloff, F., Makris, J., \& Shimamura, H. (1996). Crustal structure across the middle Ryukyu trench obtained from ocean bottom seismographic data. Tectonophysics, 263(1-4), 39-60.

Kostoglodov, V., Singh, S. K., Santiago, J. A., Franco, S. I., Larson, K. M., Lowry, A. R., \& Bilham, R. (2003). A large silent earthquake in the Guerrero seismic gap, Mexico. Geophysical Research Letters, 30(15), 1807. https://doi.org/10.1029/2003GL017219

Larson, K. M., Kostoglodov, V., Miyazaki, S., \& Santiago, J. A. S. (2007). The 2006 aseismic slow slip event in Guerrero, Mexico: New results from GPS. Geophysical Research Letters, 34, L13309. https://doi.org/10.1029/2007GL029912

Lee, C. S., Shor, G. G. Jr, Bibee, L., Lu, R. S., \& Hilde, T. W. (1980). Okinawa Trough: Origin of a back-arc basin. Marine Geology, 35(1-3), 219-241.

Letouzey, J., \& Kimura, M. (1986). The Okinawa Trough: genesis of a back-arc basin developing along a continental margin. Tectonophysics, 125(1-3), 209-230.

Lin, J. Y., Sibuet, J. C., Hsu, S. K., \& Wu, W. N. (2014). Could a Sumatra-like megathrust earthquake occur in the south Ryukyu subduction zone? Earth, Planets and Space, 66(1), 49.

Lombard, A., Cazenave, A., Le Traon, P. Y., \& Ishii, M. (2005). Contribution of thermal expansion to present-day sea-level change revisited. Global and Planetary Change, 47(1), 1-16.

Meltzner, A. J., Sieh, K., Abrams, M., Agnew, D. C., Hudnut, K. W., Avouac, J. P., \& Natawidjaja, D. H. (2006). Uplift and subsidence associated with the great Aceh-Andaman earthquake of 2004. Journal of Geophysical Research, 111, B02407. https://doi.org/10.1029/ 2005JB003891

Meltzner, A. J., Sieh, K., Chiang, H. W., Shen, C. C., Suwargadi, B. W., Natawidjaja, D. H., \& Briggs, R. W. (2012). Persistent termini of 2004-and 2005-like ruptures of the Sunda megathrust. Journal of Geophysical Research, 117, B04405. https://doi.org/10.1029/ 2011JB008888

Meltzner, A. J., Sieh, K., Chiang, H. W., Shen, C. C., Suwargadi, B. W., Natawidjaja, D. H., \& Galetzka, J. (2010). Coral evidence for earthquake recurrence and an AD 1390-1455 cluster at the south end of the 2004 Aceh-Andaman rupture. Journal of Geophysical Research, 115, B10402. https://doi.org/10.1029/2010JB007499

Meltzner, A. J., Sieh, K., Chiang, H. W., Wu, C. C., Tsang, L. L., Shen, C. C., et al. (2015). Time-varying interseismic strain rates and similar seismic ruptures on the Nias-Simeulue patch of the Sunda megathrust. Quaternary Science Reviews, 122, 258-281.

Meltzner, A. J., \& Woodroffe, C. D. (2015). Coral microatolls. Handbook of Sea-Level Research, 125-145.

Métois, M., Socquet, A., \& Vigny, C. (2012). Interseismic coupling, segmentation and mechanical behavior of the central Chile subduction zone. Journal of Geophysical Research, 117, B03406. https://doi.org/10.1029/2011JB008736

Meyssignac, B., \& Cazenave, A. (2012). Sea level: A review of present-day and recent-past changes and variability. Journal of Geodynamics, $58,96-109$.

Meyssignac, B., Salas y Melia, D., Becker, M., Llovel, W., \& Cazenave, A. (2012). Tropical Pacific spatial trend patterns in observed sea level: Internal variability and/or anthropogenic signature? Climate of the Past, 8(2), 787-802.

Mondal, D. R., McHugh, C. M., Mortlock, R. A., Steckler, M. S., Mustaque, S., \& Akhter, S. H. (2018). Microatolls document the 1762 and prior earthquakes along the southeast coast of Bangladesh. Tectonophysics, 745, 196-213.

Nakamura, M. (2004). Crustal deformation in the central and southern Ryukyu Arc estimated from GPS data. Earth and Planetary Science Letters, 217(3), 389-398.

Nakamura, M. (2006). Source fault model of the 1771 Yaeyama tsunami, southern Ryukyu Islands, Japan, inferred from numerical simulation. Pure and Applied Geophysics, 163(1), 41-54.

Nakamura, M. (2009a). Aseismic crustal movement in southern Ryukyu trench, southwest Japan. Geophysical Research Letters, 36, L20312. https://doi.org/10.1029/2009GL040357

Nakamura, M. (2009b). Fault model of the 1771 Yaeyama earthquake along the Ryukyu Trench estimated from the devastating tsunami. Geophysical Research Letters, 36, L19307. https://doi.org/10.1029/2009GL039730

Nakamura, M. (2011). Interplate coupling in the Ryukyu Trench: Possibility of large interplate earthquakes and mega-tsunamis. In Proceedings of the 10th Taiwan-Japan International Workshop on Hydrological and Geochemical Research for Earthquake Prediction, Open File Report of Geological Survey of Japan (Vol. 574, pp. 19-28). 
Nakamura, M. (2017). Distribution of low-frequency earthquakes accompanying the very low frequency earthquakes along the Ryukyu Trench. Earth, Planets and Space, 69(1), 49.

Nakamura, M., \& Sunagawa, N. (2015). Activation of very low frequency earthquakes by slow slip events in the Ryukyu Trench. Geophysical Research Letters, 42, 1076-1082. https://doi.org/10.1002/2014GL062929

Nakata, T., \& Kawana, T. (1995). Historical and prehistorical large tsunamis in the southern Ryukyus, Japan. In Y. Tsuchiya, \& N. Shuto (Eds.), Tsunami: Progress in prediction, disaster prevention and warning (Vol. 4, pp. 211-221). Dordrecht: Springer.

Natawidjaja, D. H., Sieh, K., Chlieh, M., Galetzka, J., Suwargadi, B. W., Cheng, H., \& Ward, S. N. (2006). Source parameters of the great Sumatran megathrust earthquakes of 1797 and 1833 inferred from coral microatolls. Journal of Geophysical Research, 111, B06403. https://doi.org/10.1029/2005JB004025

Nishimura, T. (2014). Short-term slow slip events along the Ryukyu Trench, southwestern Japan, observed by continuous GNSS. Progress in Earth and Planetary Science, 1(1), 22.

Nishimura, S., Hashimoto, M., \& Ando, M. (2004). A rigid block rotation model for the GPS derived velocity field along the Ryukyu arc. Physics of the Earth and Planetary Interiors, 142(3-4), 185-203.

Nishizawa, A., Kaneda, K., Oikawa, M., Horiuchi, D., Fujioka, Y., \& Okada, C. (2017). Variations in seismic velocity distribution along the Ryukyu (Nansei-Shoto) Trench subduction zone at the northwestern end of the Philippine Sea plate. Earth, Planets and Space, 69(1), 86.

Nocquet, J. M., Jarrin, P., Vallée, M., Mothes, P., Grandin, R., \& Rolandone, F. (2017). Supercycle at the Ecuadorian subduction zone revealed after the 2016 Pedernales earthquake. Nature Geoscience, 10(2), 145.

Okada, Y. (1992). Internal deformation due to shear and tensile faults in a half-space. Bulletin of the Seismological Society of America, 82(2), $1018-1040$.

Okamura, Y., Nishizawa, A., Fujii, Y., \& Yanagisawa, H. (2018). Accretionary prism collapse: A new hypothesis on the source of the 1771 giant tsunami in the Ryukyu Arc, SW Japan. Scientific reports, 8(1), 13620.

Ota, Y., Kawana, T., \& Moriwaki, H. (1985). Late Holocene coastal morphology and sea-level records on three small islands, the South Ryukyus, Japan. Geographical Review of Japan, Series B., 58(2), 185-194.

Peterson, E. T., \& Seno, T. (1984). Factors affecting seismic moment release rates in subduction zones. Journal of Geophysical Research, 89(B12), 10,233-10,248

Philibosian, B., Sieh, K., Avouac, J. P., Natawidjaja, D. H., Chiang, H. W., Wu, C. C., \& Suwargadi, B. W. (2014). Rupture and variable coupling behavior of the Mentawai segment of the Sunda megathrust during the supercycle culmination of 1797 to 1833 . Journal of Geophysical Research: Solid Earth, 119, 7258-7287. https://doi.org/10.1002/2014JB011200

Philibosian, B., Sieh, K., Natawidjaja, D. H., Chiang, H. W., Shen, C. C., Suwargadi, B. W., \& Edwards, R. L. (2012). An ancient shallow slip event on the Mentawai segment of the Sunda megathrust, Sumatra. Journal of Geophysical Research, 117, B05401. https://doi.org/ 10.1029/2011JB009075

Pirazzoli, P. A., \& Koba, M. (1989). Late Holocene sea-level changes in Iheya and Noho Islands, the Ryukyus, Japan. Earth Science (Chikyu Kagaku), 43(1), 1-6.

Rolandone, F., Nocquet, J. M., Mothes, P. A., Jarrin, P., Vallée, M., Cubas, N., \& Font, Y. (2018). Areas prone to slow slip events impede earthquake rupture propagation and promote afterslip. Science advances, 4(1), eaao6596.

Ruiz, S., Metois, M., Fuenzalida, A., Ruiz, J., Leyton, F., Grandin, R., \& Campos, J. (2014). Intense foreshocks and a slow slip event preceded the 2014 Iquique Mw 8.1 earthquake. Science, 345(6201), 1165-1169.

Sasaki, Y. N., Washizu, R., Yasuda, T., \& Minobe, S. (2017). Sea level variability around Japan during the twentieth century simulated by a regional ocean model. Journal of Climate, 30(14), 5585-5595.

Sato, T., Koresawa, S., Shiozu, Y., Kusano, F., Uechi, S., Nagaoka, O., \& Kasahara, J. (1994). Microseismicity of back-arc rifting in the middle Okinawa Trough. Geophysical Research Letters, 21(1), 13-16.

Savage, J. (1983). A dislocation model of strain accumulation and release at a subduction zone. Journal of Geophysical Research, 88(B6), 4984-4996.

Scholz, C., \& Campos, J. (1995). On the mechanism of seismic decoupling and back arc spreading at subduction zones. Journal of Geophysical Research, 100(B11), 22,103-22,115.

Scoffin, T. P., Stoddart, D., \& Rosen, B. R. (1978). The nature and significance of microatolls. Philosophical Transactions of the Royal Society of London. B, Biological Sciences, 284(999), 99-122.

Shen, C. C., Li, K. S., Sieh, K., Natawidjaja, D., Cheng, H., \& Wang, X. (2008). Variation of initial ${ }^{230} \mathrm{Th} /{ }^{232} \mathrm{Th}$ and limits of high precision U-Th dating of shallow-water corals. Geochimica et Cosmochimica Acta, 72(17), 4201-4223.

Shyu, J. B. H., Wang, C. C., Wang, Y., Shen, C. C., Chiang, H. W., Liu, S. C., \& Tun, S. T. (2018). Upper-plate splay fault earthquakes along the Arakan subduction belt recorded by uplifted coral microatolls on northern Ramree Island, western Myanmar (Burma). Earth and Planetary Science Letters, 484, 241-252.

Sibuet, J. C., Deffontaines, B., Hsu, S. K., Thareau, N., Formal, L., \& Liu, C. S. (1998). Okinawa trough backarc basin: Early tectonic and magmatic evolution. Journal of Geophysical Research, 103(B12), 30,245-30,267.

Sibuet, J. C., Letouzey, J., Barbier, F., Charvet, J., Foucher, J. P., \& Hilde, T. W. (1987). Back arc extension in the Okinawa Trough. Journal of Geophysical Research, 92(B13), 14,041-14,063.

Sieh, K., Natawidjaja, D. H., Meltzner, A. J., Shen, C. C., Cheng, H., Li, K. S., \& Edwards, R. L. (2008). Earthquake supercycles inferred from sea-level changes recorded in the corals of west Sumatra. Science, 322(5908), 1674-1678.

Smithers, S. (2011). Moating. In Encyclopedia of Modern Coral Reefs (pp. 711-712): Springer.

Smithers, S. G., \& Woodroffe, C. D. (2000). Microatolls as sea-level indicators on a mid-ocean atoll. Marine Geology, 168(1), 61-78.

Stoddart, D. R., \& Scoffin, T. P. (1979). Microatolls: Review of form, origin, and terminology. Smithsonian Institution.

Sun, T., Wang, K., Iinuma, T., Hino, R., He, J., \& Fujimoto, H. (2014). Prevalence of viscoelastic relaxation after the 2011 Tohoku-oki earthquake. Nature, 514(7520), 84

Tadokoro, K., Nakamura, M., Ando, M., Kimura, H., Watanabe, T., \& Matsuhiro, K. (2018). Interplate coupling state at the Nansei-Shoto (Ryukyu) Trench, Japan, deduced from seafloor crustal deformation measurements. Geophysical Research Letters, 45, 6869-6877. https:// doi.org/10.1029/2018GL078655

Taylor, F. W., Frohlich, C., Lecolle, J., \& Strecker, M. (1987). Analysis of partially emerged corals and reef terraces in the central Vanuatu arc: Comparison of contemporary coseismic and nonseismic with Quaternary vertical movements. Journal of Geophysical Research, 92(B6), 4905-4933.

Taylor, F., Isacks, B., Jouannic, C., Bloom, A., \& Dubois, J. (1980). Coseismic and Quaternary vertical tectonic movements, Santo and Malekula Islands, New Hebrides island arc. Journal of Geophysical Research, 85(B10), 5367-5381.

Taylor, F. W., Jouannic, C., Gilpin, L., \& Bloom, A. (1982). Coral colonies as monitors of change in relative level of the land and sea: Applications to vertical tectonism. Proceedings of 4th international coral reef congress, p. 485-492. 
Tsuji, Y. (1997). Damage to Villages on Amami Archipelago due to the 1995 Amami-Oshima-Kinkai Earthquake-Tsunami. Journal of Geography (Chigaku Zasshi), 106(4), 486-502.

Usami, T. (1996). Materials for comprehensive list of destructive earthquakes in Japan.

Vigny, C., Socquet, A., Peyrat, S., Ruegg, J. C., Métois, M., \& Madariaga, R. (2011). The 2010 Mw 8.8 Maule megathrust earthquake of central Chile, monitored by GPS. Science, 332(6036), 1417-1421.

Villamor, P., \& Berryman, K. (2001). A late Quaternary extension rate in the Taupo Volcanic Zone, New Zealand, derived from fault slip data. New Zealand Journal of Geology and Geophysics, 44(2), 243-269.

Wallace, L. M., \& Beavan, J. (2006). A large slow slip event on the central Hikurangi subduction interface beneath the Manawatu region, North Island, New Zealand. Geophysical Research Letters, 33, L11301. https://doi.org/10.1029/2006GL026009

Watanabe, H. (1985). A comprehensive list of tsunami damage in Japan. University of Tokyo Press, Tokyo (in Japanese).

Watanabe, T., \& Tabei, T. (2004). GPS velocity field and seismotectonics of the Ryukyu arc, southwest Japan. Journal of the Seismological Society of Japan, 57(1), 1-10.

Weil-Accardo, J., Feuillet, N., Jacques, E., Deschamps, P., Beauducel, F., Cabioch, G., \& Galetzka, J. (2016). Two hundred thirty years of relative sea level changes due to climate and megathrust tectonics recorded in coral microatolls of Martinique (French West Indies). Journal of Geophysical Research: Solid Earth, 121, 2873-2903. https://doi.org/10.1002/2015JB012406

Weil-Accardo, J., Feuillet, N., Jacques, E., Deschamps, P., Saurel, J. M., Thirumalai, K., \& Anglade, D. (2016). Relative sea-level changes during the last century recorded by coral microatolls in Belloc, Haiti. Global and Planetary Change, 139, 1-14.

Woodroffe, C. D., \& Gagan, M. K. (2000). Coral microatolls from the central Pacific record late Holocene El Nino. Geophysical Research Letters, 27(10), 1511-1514.

Woodroffe, C., \& McLean, R. (1990). Microatolls and recent sea level change on coral atolls.

Wöppelmann, G., \& Marcos, M. (2016). Vertical land motion as a key to understanding sea level change and variability. Reviews of Geophysics, 54, 64-92. https://doi.org/10.1002/2015RG000502

Yonekura, N., Kayanne, H., Matsumoto, E., Ishii, T., Matsushima, Y., Hori, N., \& Nakai, T. (1994). Geomorphic development of modern fringing reefs of Yoron Island, Ryukyu Arc, Japan. The Quaternary Research (Daiyonki-Kenkyu), 33(2), 67-79.

Zachariasen, J. A. (1998). Paleoseismology and paleogeodesy of the Sumatran subduction zone: A study of vertical deformation using coral microatolls. California Institute of Technology.

Zachariasen, J., Sieh, K., Taylor, F. W., Edwards, R. L., \& Hantoro, W. S. (1999). Submergence and uplift associated with the giant 1833 Sumatran subduction earthquake: Evidence from coral microatolls. Journal of Geophysical Research, 104(B1), 895-919.

Zachariasen, J., Sieh, K., Taylor, F. W., \& Hantoro, W. S. (2000). Modern vertical deformation above the Sumatran subduction zone: Paleogeodetic insights from coral microatolls. Bulletin of the Seismological Society of America, 90(4), 897-913. 